\title{
Economía Pública y corrupción. Una ordenación de las propuestas anticorrupción
}

\section{José M. March Poquet}

RESUMEN: La corrupción en la economía pública en España está generando muchas y muy diversas propuestas de medidas para combatirla. En este trabajo se presenta un método de ordenación de dichas medidas a partir de una combinación de dos teorías criminológicas, la Teoría de las Expectativas Racionales y la Teoría de las Actividades Rutinarias. El método distingue cuatro espacios de riesgo de corrupción articulados en torno al ciclo de las políticas públicas: delincuentes, guardianes, escenarios y víctimas. En cada uno de estos espacios la política anticorrupción posee una naturaleza diferente y, en consecuencia, unos objetivos e instrumentos específicos.

El método que se propone permite ubicar cada propuesta en un espacio concreto y así obtener una visión panorámica de las mismas, a partir de la cual se pueden hacer valoraciones desde una perspectiva integral de lucha contra la corrupción pública. En particular, facilita la identificación de ámbitos en los cuáles hay insuficiencia o duplicidades de propuestas, incoherencias e incompatibilidades, así como círculos viciosos (que retroalimentan la corrupción) y virtuosos (que aceleran su reducción). Más allá de las medidas específicas, permite comparar planes anticorrupción, facilitando las evaluaciones técnicas y políticas a priori y su posible integración. Por último, puede ayudar a elaborar cronogramas para combinar medidas cuya efectividad responda a tiempos políticos diferentes.

PALABRAS CLAVE: Corrupción pública, economía pública, ciclo de políticas públicas, régimen de obediencia, medidas anticorrupción, método de ordenación de medidas anticorrupción.

CLAVES ECONLIT: H11, K42, H57.

Cómo citar este artículo / How to cite this article: MARCH, J.M. (2017): "Economía Pública y corrupción. Una ordenación de las propuestas anticorrupción", CIRIEC-España, Revista de Economía Pública, Social y Cooperativa, 91, 267-303.

Correspondencia: José M. March Poquet, Profesor Titular de Universidad, Departamento de Economía Aplicada, Universitat de València. E-mail: march@uv.es. 


\section{EXPANDED ABSTRACT}

\section{Public Economy and Corruption. An ordering of anti-corruption proposals}

Corruption is one of the most worrying problems currently in Spain. Its damage to the public economy has become visible and unquestionable. Moreover, there is a sense of impunity for the corrupt that de-legitimizes the democratic system and is provoking the political disaffection of many Spaniards. However, there has been some civic response that calls for reforms and there is a proliferation of proposals for measures to combat corruption. These are measures of very diverse nature and scope. This generates a sense of chaos and improvisation. We consider that it is only apparent chaos, that behind these proposals there is a logic that arises from the particular perspective and concern of the one who proposes it.

The object of study is the Spanish case of public corruption, although we do not have a precise definition nor with universal validity. It is logical because the phenomena of corruption are complex, multidimensional, with a strong moral burden and each one approaches them in their own way according to their analytical interest. Here we do not propose another one of definition, we are enough with the definition umbrella habitual: "abuse of power in private benefit". In the Spanish case, although corruption itself is not typified, there are crimes of "corrupt type". However, we have expanded the subject of study beyond the crimes of corruption typified in the law, incorporating other forms of "abuse of power (public) in private benefit" that may even they be legal. They are not crimes that a court can judge, but they are "bad manners" of doing things that citizens can punish with their vote, if they want.

The approach taken to deal with this issue is based on the fact that the relationship between the citizen and the politician is of "principal-agent" and that is developed in a market of "lemons". The Agency Theory, although developed for the private sector, serves to address the issue of delegated responsibility in the field of public policies. In an advanced democracy, each voter decides who has her trust to management their priority interests from public institutions. From that moment on, the citizen (principal) is in the hands of the politician (agent) until the next elections (electoral cycle), during which the agent has to account for his management to the principal. Then the citizen can reaffirm his confidence in a certain politician, his questioning or his withdrawal. But it is not easy to make that decision because the information is asymmetric: the politician knows what's really behind his story, but the voter not, he only has signals. This refers us to the market of "lemons". The voter knows that he participates in a political market of lemons, in which the candidates, to win, promise beyond their pos- 
sibilities and hide their limitations, even lie. The voter's responses to a politician he distrusts may be mainly: give him another chance (loyalty), claim him to do better (voice) or trust another politician (exit). When he does not trust any politician the reactions are the same but the consequences not; in this case the exit is of the whole political market (disaffection), the voice calls for changes but not in the political one but in the functioning of the whole system (for example, transparency). We are especially interested in the voice, particularly the one that claims less public corruption (both typified and paracorruption).

The objective of this work is to order the different proposals in some way that allows us to obtain an overview. To this end we have considered that public corruption is a crime, albeit with specific traits, and we have resorted to Criminology. In particular, we have integrated the Theory of Rational Expectations (TRE) and the Routine Activity Theory (RAT) as working hypothesis. The first allows us to make explicit the rationality of the corrupt. The second allows us to incorporate three key elements: victims, guardians and crime scene. We have adapted TRE+RAT to our object of study: crime is corruption, criminals are corrupt, guardians are those who face corruption, victims are citizens in general and change of routines or lifestyle is, in the Spanish case, the political-institutional reform initiated with the Transition. Combining both theories we have four basic elements (delinquent, victim, guardian and scene) that explain the most recommended criminal (preventive) policy measures: discourage potential criminals (motivated offenders), more trained guardians (capable guardianship), restructure crime scenarios to reduce exposure to the risk of crime and educate potential victims to be more careful.

Starting from a review (not exhaustive) of the proposals made both for the particular situation of Spain and for this phenomenon in general, has analyzed the nature of each of them. This analysis has allowed to classify them according to which of the previous elements is affected. In the case of the corrupt (criminals) four types of proposals have been identified: those that increase the opportunity cost of performing a corrupt act, those that reduce the income obtained with it, those that increase their costs and those that increase the sanctions. With regard to the guardians, four main types have been identified: those proposing more/new guardians and those seeking to increase their effectiveness both police and judicial and deterrent. Regarding the crime scenario, the cycle of public policy, three types have been identified: those that aim to improve this scenario, but also to improve political procedures and actors involved in the cycle. Finally, with regard to the victims, measures have been identified which seek to increase their knowledge of the crime, their ability to fight it and their willingness to act against it.

The result obtained is a kind of map that allows to locate the anti-corruption proposals in fourteen different territories, articulated around the cycle of public policies. This map can be a useful tool for the analysis of anti-corruption policies, in particular it facilitates:

- discovering territories that are left out of the anti-corruption measures (unprotected) and others that are overloaded with measures; 
- identify inconsistencies and incompatibilities between different proposals;

- detect vicious circles of corruption (more harmful) and virtuous circles of corruption reduction (more effective in the fight against this crime);

- assess which territories are the most appropriate to concentrate the resources aimed at combating corruption and in which may have an excess;

- to use a common language in the interdisciplinary discussion, since proposing a map that integrates the political, economic, juridical and sociological visions;

- improve synchronization between measures that have different maturing times, that is, the political times

KEYWORDS: Public corruption, public economy, public policy cycle, obedience regime, anti-corruption measures, method of ordering anti-corruption measures. 


\section{1.- Introducción}

En los últimos años la corrupción ha dañado seriamente a la economía pública española. La reacción ha sido una "tormenta de ideas" sobre cómo combatirla. El objetivo de este trabajo es proponer una manera de ordenar esa tormenta aparentemente caótica. Aquí se defiende que cada propuesta surge de una percepción y preocupación particular más o menos acertada, pero que responde a alguna lógica. No proponemos nuevas soluciones ni las valoramos, sólo se intenta poner cada una en un determinado lugar de una especie de mapa de ordenación del territorio de la corrupción (ver Diagrama 1), para poder apreciar qué imagen hay detrás de ese puzle de propuestas.

La estructura de la exposición es la siguiente. En el primer apartado se delimita el objeto de estudio, se hace explícita la perspectiva teórica adoptada y se establece la hipótesis de trabajo a partir de la cual se realiza la ordenación. En los siguientes apartados se describe cada uno de los cuatro espacios o territorios que componen el mapa de ordenación, la naturaleza de las soluciones propuestas respecto a dicho espacio y se muestran algunos ejemplos ilustrativos. Se finaliza con una recapitulación.

Algunas advertencias previas. Primera, las referencias a trabajos sobre propuestas anticorrupción no implican que sus autores defiendan dichas propuestas. Segunda, algunas propuestas pueden ser clasificadas en varios territorios; se ha optado por uno en concreto para simplificar la exposición. Tercera, las soluciones que se mencionan no constituyen una lista exhaustiva, muchas se han quedado en el tintero, son sólo ejemplos ilustrativos. Cuarta, si se ha interpretado incorrectamente alguna propuesta, la culpa es exclusivamente del que escribe. Y quinta, aunque algunos casos mencionados aquí ya han sido resueltos con sentencia judicial en firme, los sujetos a los que se hace referencia son inocentes mientras no se demuestre lo contrario.

\section{2.- Objeto, perspectiva e hipótesis de trabajo}

Objeto: Todos tenemos una idea de a qué nos referimos cuando se habla de corrupción, pero no disponemos de una definición precisa y de validez universal. Es lógico porque los fenómenos de corrupción son complejos, multidimensionales, con una fuerte carga moral y cada cual los aborda a su manera según su interés analítico (Bussell, 2015). Aquí no vamos a hacer otro intento de definición, nos basta con la "definición paraguas" al uso (Rose-Ackerman y Truex, 2012: 3): "abuso de poder en beneficio pri- 
vado". Aunque la delimitamos así: excluimos la estrictamente privada, nos interesa especialmente la que afecta a lo que más adelante denominamos ciclo de las políticas públicas y, aunque consideramos lo que se dice en otras latitudes, nuestra referencia directa es la corrupción "Marca España".

En la esfera de lo público existen unas reglas del juego, algunas formales y otras informales, que en cada sociedad (delimitada por un espacio y tiempo determinados) cristalizan de forma particular y se respetan y se sanciona su incumplimiento en grados diferentes de rigor. Algunos de los incumplimientos están contemplados en la Ley. En el caso español, aunque la corrupción en sí no está tipificada (Lapuente, 2016: 108), sí existen delitos de "tipo corrupto". Pero otras formas de "abuso de poder (público) en beneficio privado" no lo están, incluso pueden ser (a)legales. Esas también nos interesan y nos referiremos a ellas como para-corrupción. Según el diccionario, corrupción es "Echar a perder, depravar, dañar o pudrir algo" y también "Hacer que algo se deteriore" (DRAE). Para nosotros ese "algo" es la política pública. Si a todos los actos que la echan a perder, depravan, dañan, pudren o deterioran le restamos las formas de corrupción tipificadas, obtenemos lo que es para-corrupción. No son delitos que un tribunal pueda juzgar, pero sí son "malas maneras" de hacer las cosas que los ciudadanos pueden castigar, si quieren. Esto nos remite al "problema de la agencia", clave en nuestro enfoque teórico.

Perspectiva. La teoría de la agencia, aunque desarrollada para el ámbito privado, nos sirve para abordar el asunto de la responsabilidad delegada en el ámbito de las políticas públicas (Banfield, 1975; Aidt, 2003). En una democracia avanzada cada votante decide en quién deposita su confianza para que gestione sus intereses prioritarios desde las instituciones públicas. En el caso español, el resultado electoral global determina la composición de los órganos legislativos y éstos la de los ejecutivos (en los distintos niveles de un Estado descentralizado). A partir de ese momento, el ciudadano (principal) está en manos del político (agente) hasta las próximas elecciones (ciclo electoral), durante las cuales el agente ha de rendir cuentas de su gestión ante el principal. Los gobiernos despliegan sus políticas y el ciudadano va percibiendo señales de cómo están evolucionado las cosas, especialmente su situación. Cuando el ciclo termina, los candidatos electorales exponen sus relatos de esa evolución y los proyectan hacia el futuro y el ciudadano puede contrastarlos con sus percepciones. Esta contrastación puede provocar la reafirmación de su confianza en determinado político, su cuestionamiento o su retirada. Pero no es fácil hacer ese contraste porque la información es asimétrica; el político sabe qué hay realmente detrás de su relato pero el votante no, sólo dispone de señales. Esto nos remite al "mercado de los limones" (Akerlof, 1970).

El votante no es un ingenuo, sabe que participa en un mercado de limones político, en el que los candidatos, para venderse, prometerán por encima de sus posibilidades y ocultarán sus limitaciones, incluso engañarán (Jeambar y Roucaute, 1999). Aquí la credibilidad del político es un factor relevante, éste se presenta con una reputación construida en el pasado por él o por su partido. Una reputación sana permite gobernar durante dos o incluso tres legislaturas consecutivas pero, antes 0 después, se deteriora y, cuando caiga por debajo de la línea de flotación, el votante tendrá tres posibilidades, la lealtad, la voz y la salida (Hirschman, 1977). 
Las respuestas del votante hacia un político en el que desconfía pueden ser principalmente: darle otra oportunidad (lealtad), reclamarle que lo haga mejor (voz) o confiar en otro (salida). Cuando no confía en ningún político las reacciones son las mismas pero las consecuencias no; en este caso la salida es de todo el mercado político (desafección), la voz reclama cambios pero no en el político sino en el funcionamiento de todo el sistema (por ejemplo, transparencia y rendición de cuentas) y la lealtad podría interpretarse como resignación (considera que los políticos no valen, pero el sistema sí). Nos interesa especialmente la voz, que está a caballo entre resignarse a esperar nuevas hornadas de políticos y desconectar de la política, y particularmente aquella que reclama menos corrupción en lo público, tanto la tipificada como la para-corrupción. Vamos a intentar ordenar esas voces utilizando como criterio de ordenación una hipótesis de trabajo que denominaremos TER+TAR.

Hipótesis de trabajo. Si consideramos que la corrupción es un crimen, aunque con variables explicativas particulares (Lederman, Loayza y Reis, 2001), podemos recurrir a la Criminología. En esta disciplina existen muchas y muy variadas teorías explicativas de los fenómenos criminales (véase, por ejemplo, Walsh y Hemmens, 2011) pero, dado nuestro interés, nos basta con dos de ellas.

TER. La Teoría de la Elección Racional (TER) recuperó en los años ochenta del siglo veinte el enfoque utilitarista clásico de Bentham. El criminal regula su tendencia natural al libre albedrio mediante una racionalidad fundamentada en dos principios: maximizar su placer y minimizar su sufrimiento. Ambos principios actúan en un entorno en el que existe una constelación de oportunidades, costos y beneficios asociados a tipos particulares de delitos (Cornish y Clarke, 2003). Es decir, el delincuente tiene una "cuenta de explotación" parecida a la de cualquier homo económico, pero con una variación importante, existe el riesgo de ser sancionado. Se podría formular así (la E significa que es una esperanza matemática):

Ecuación 1. TER

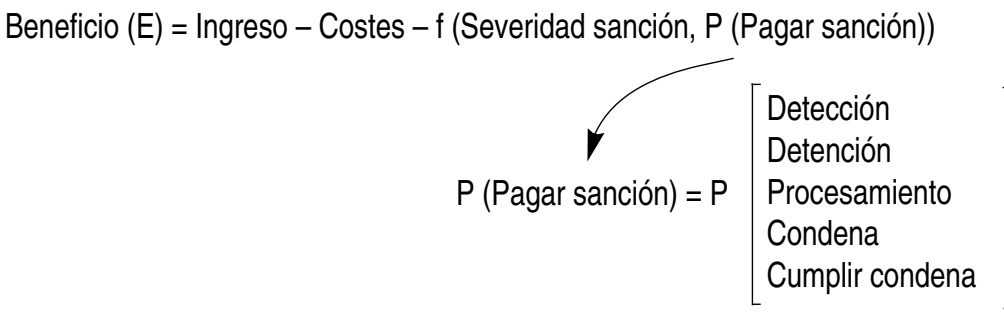

Ingreso es el botín que logra mediante el acto corrupto; no se trata sólo del dinero que logra con su "mordida", también pueden ser intangibles, como construir una reputación de "buen amigo" capaz de colocar a su gente en cargos públicos bien remunerados; en palabras de un político castellonense: "Yo no sé a la gente que habré colocado" (Castillo, 2016). Los costes corresponden a los gastos necesarios para realizar (y reproducir si es posible) los actos corruptos; principalmente son gastos de ocul- 
tación (empresas tapadera, testaferros, gastos de lavado de dinero sucio...) y gastos de protección (gabinetes de abogados, sobornos a policías y jueces...). La sanción o pena es un coste muy particular pues es una magnitud incierta y debe ser ponderada con una combinación de probabilidades $(P$ significa "probabilidad de": ser detectado, detenido, procesado, condenado y de cumplir la condena). El corrupto intentará que esta probabilidad conjunta sea la menor, las autoridades lo contrario.

TAR. La Teoría de las Actividades Rutinarias (TAR) (también conocida como teoría del estilo de vida) fue formulada originalmente por Cohen y Felson (1979) e intentaba explicar por qué había aumentado tanto el ratio de crímenes en los Estados Unidos de América durante el período 1947-1974. La mayoría de los investigadores asumían que esta ratio crece cuando hay más "criminales motivados", sin embargo, dicho período fue de crecimiento económico, que se traducía en más empleo, incremento de ingresos y, en general, menos necesidad de recurrir al crimen para sobrevivir (lo contrario de lo ocurrido durante la Gran Depresión). Estos autores ofrecieron una explicación distinta que no implicaba un aumento de los delincuentes, sino que se fundamentada en un cambio en las actividades rutinarias de la población, en su estilo de vida. El período de expansión económica significó el crecimiento del empleo para los hombres y también la incorporación al mundo laboral de muchas mujeres. Esto se tradujo en que durante la jornada laboral más hogares quedaban vacíos y las calles de los barrios residenciales menos concurridas, por tanto, en más objetivos atractivos para los ladrones (target suitability) y menos protegidos por guardianes (capable guardianship), con independencia de que hubiese o no más delincuentes (motivated offenders).

TER + TAR. Adaptamos la hipótesis de trabajo a nuestro objeto de estudio: el delito es la corrupción, los delincuentes son los corruptos, los guardianes son aquellos que se enfrentan a la corrupción, las víctimas son los ciudadanos en general y el cambio de rutinas o de estilo de vida es, en el caso español, la reforma político-institucional iniciada con la Transición. Combinando ambas teorías disponemos de cuatro elementos básicos (delincuente, víctima, guardián y entorno) que explican las medidas de política criminal (preventiva) más recomendadas:

1. Desmotivar a los delincuentes potenciales: penas más severas, mayor eficacia policial (detección y detención) y mayor eficacia judicial (procesamiento y condena).

2. Más guardianes capacitados: más policías bien preparados y motivados y más dotaciones de recursos materiales, técnicos y organizativos.

3. Reestructurar los escenarios del crimen para reducir la exposición al riesgo del delito: cajas fuertes, alarmas y cámaras de vigilancia, patrullas en las calles...

4. Educar a las víctimas potenciales para que sean más cuidadosas: echar el cerrojo de la puerta, tomar precauciones al entrar en el parking, que un vecino vacíe el buzón de correo durante nuestras vacaciones... 


\section{Diagrama 1. Mapa de ordenación}

DELINCUENTES Beneficio $(E)=$ Ingreso - Costes $-f($ Severidad sanción, $P$ (Cumplir condena))

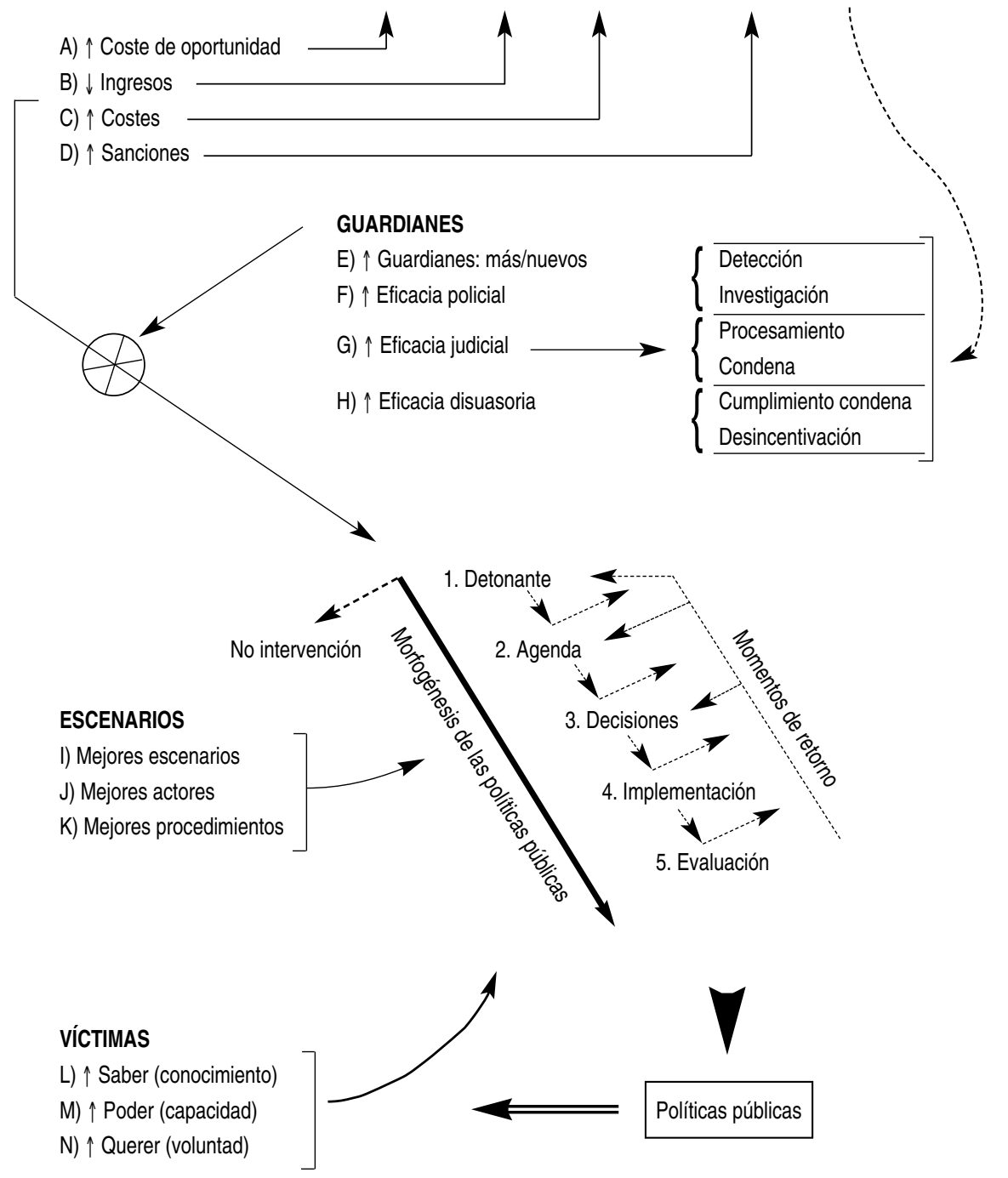

FUENTE: Elaboración propia. 


\section{3.- Delincuentes (motivados)}

Quiénes son. La imagen más inmediata de la corrupción es la del binomio corruptor-corrupto ("It takes two to tango"; Lapalombara, 1994: 34). Por ejemplo, un alcalde se empeñó en que se le adjudicara el servicio de recogida de basura a una empresa "amiga"; para ello vulneró el pliego de condiciones establecido e incluso falseó informes técnicos externos para rebatir los informes internos que eran contrarios a esta concesión (Correcher, 2015: 25). Pero también hay casos de auto-corrupción, en los que corruptor y corrupto es la misma persona, un lobo solitario. Por ejemplo, un funcionario municipal se encargaba de la recaudación de los impuestos locales. Al final del año rendía cuentas al consistorio. Posteriormente esta función recaudatoria se trasladó a la Diputación Provincial. Entonces se descubrió que el funcionario había cobrado recibos que no reembolsó al Ayuntamiento (constaban como impagados) (Correcher, 2015: 45). En otros casos el lobo solitario incita a terceros y consigue arrastrarlos consigo como cooperadores. Por ejemplo, una funcionaria de la Agencia Tributaria encargada de la gestión del IVA compinchó a unos familiares para solicitar devoluciones del IVA de actividades económicas que no existían realmente (Correcher, 2015: 52). Pero el estadio superior de desarrollo de la corrupción es el de la trama, en la que participan figuras que implican una división de tareas, en cierta manera, especializadas. Veamos cuáles son.

El intermediario, que sugiere continuidad en la comisión del delito. Algunos ejemplos. Carlos Fabra fue investigado por supuestas comisiones obtenidas por intermediar en la obtención de licencias de fabricación y comercialización de productos fitosanitarios ante los ministerios responsables e incluso creó una empresa para encubrir este tipo de ingresos (Castillo, 2013: 74 y 2016: 119). El extesorero de Alianza Popular, Ángel Sanchís, en sus declaraciones sobre el caso Naseiro, afirmó que "la CEOE actuaba como correa de trasmisión para recaudar fondos entre los empresarios" y Luís Bárcenas considera que la función del tesorero de su partido era la de un intermediario que recibe donaciones "no finalistas" de empresarios, pero que posteriormente facilitarían que el donante accediese a determinados ministros (Gallero, 2015: 106, 322 y 354).

El conseguidor es otra figura, derivada de la anterior. Añade a la continuidad en el tiempo la captación activa de nuevos clientes-corruptores. Según Jorge Verstrynge, que fue secretario general de Alianza Popular cuando aún no existía Ley de Financiación de Partidos Políticos, "en aquel momento a quien daban el dinero era al PSOE; a nosotros muy poquito (...) ¡Aquello era el salvaje Oeste! Había que recaudar dinero de debajo de las piedras" (Gallero, 2015: 106). Y según declaró Bárcenas ante el juez Ruz, a menudo es un cargo electo del partido a nivel regional o provincial quien recomienda al tesorero ponerse en contacto con personas interesadas en colaborar financieramente con el partido (Ekaizer, 2015: 261). 
La tapadera es una tercera figura que complementa las anteriores; son entidades que permiten borrar huellas o desviar las responsabilidades hacia determinados puntos de la trama. Su función principal es ocultar para mermar la eficacia policial. Por ejemplo, el caso Filesa destapó una trama de financiación ilegal del PSOE apoyada en tres sociedades (Filesa, Malesa y Time-Export); utilizaban un diseño triangular: empresas-tapadera-partido; las tapaderas realizaban estudios o servicios inexistentes o innecesarios que cobraban a bancos y grandes empresas y con ello pagaban a los proveedores del partido por sus gastos electorales (Pradera, 2014: 85; Garzón, 2015: 93 y ss). Otro ejemplo; SIPSA y OPISA fueron dos de las empresas tapadera creadas para financiar Alianza Popular, que según Verstrynge, pedían y recibían dinero de eléctricas y bancos y, en el caso de emitir facturas, se hacían "informes genéricos sobre el sector para justificar el pago" (Gallero, 2015: 107; Ekaizer, 2015: 134); estas empresas se liquidaron en 1986 pero, hacia 1990, el ahora Partido Popular retomó el sistema con nuevas tapaderas (Ibérica de Filmes, Videosoluciones y Ediciones Conosur) (Ekaizer, 2015: 136-137). Un último ejemplo; según la Agencia Tributaria, Francisco Correa, líder de la trama Gürtel, llegó a tener ochenta empresas que formaban una "compleja red de pagos, sobornos y evasión de impuestos, evitando siempre cualquier tipo de control fiscal" (Castillo, 2013: 96).

El protector es la última figura que vamos a considerar. Su función refuerza la de las tapaderas, pues protege a la cadena en caso de ser detectada mediante el bloqueo de las fases de detención, procesamiento o condena o el desvío de las acusaciones hacia "cabezas de turco". Algunos ejemplos. En el caso de los prostíbulos Riviera y Saratoga en Castelldefels se trató de protección policial. Un grupo de policías avisaba a los dueños de los burdeles sobre inspecciones y controles policiales y, así, éstos podían prepararse para minimizar el impacto. A cambio recibían pagos, regalos y acceso gratuito a los servicios de los prostíbulos (Garzón, 2015: 355). En el caso Bardellino, fueron un juez del Tribunal Supremo y un fiscal de la Audiencia Nacional quienes ordenaron la puesta en libertad de este capo de la Camorra, detenido en espera de su extradición. La Justicia italiana quedó perpleja y el capo se esfumó tras pagarles unos diez millones de pesetas (Garzón, 2015: 385). En tiempos de la Operación Malaya, la televisión local de Marbella emitió un programa sobre uno de sus principales implicados, Juan Antonio Roca. Éste denunció a la televisión porque atentaba contra su honor e imagen. El juez Urquía la admitió y ordenó la suspensión del programa. El abogado de la televisión alegó que las formas eran incorrectas, debía ser una querella y no una denuncia y no se había recurrido al acto de conciliación. El juez corrigió el error: "llamó por teléfono a Roca para explicarle lo ocurrido y darle instrucciones de lo que debía hacer si quería que el programa de televisión no fuera emitido" (Garzón, 2015: 397). Por último, el propio Gobierno puede ser el protector recurriendo a la amnistía fiscal, que puede considerarse una forma de indulto cuanto menos polémica, hasta el punto de que el propio Ministro de Hacienda (defensor de la última realizada, bajo otra denominación) ha propuesto recientemente prohibirlas por ley (Tahiri, 2017). Lo mismo ocurre con la ley de indultos, que sigue salvando de prisión a corruptos, en algunos casos concedidos con una rapidez "meteórica" a pesar de informes en contra del Tribunal Supremo (Garzón, 2015: 403). 
En suma, los actores de la corrupción van más allá del típico binomio y varían desde el lobo solitario hasta tramas que pueden llegar a ser tan sofisticadas e impenetrables como las organizaciones criminales. Precisamente esta figura por fin parece comenzar a emplearse en los casos de tramas de corrupción, aunque la forma en que se incorporó al código penal sigue siendo fuente de problemas conceptuales y prácticos (Méndez, 2014).

Soluciones. Hemos clasificado las propuestas anticorrupción referidas al territorio "delincuentes" en cuatro subgrupos a partir la ecuación de su beneficio esperado (ver Diagrama 1).

A: $\uparrow$ Coste de oportunidad. El coste de oportunidad es aquello a lo que renunciamos cuando tomamos una determinada decisión 0 , si se prefiere, el valor de la mejor opción no realizada. Si un funcionario opta por corromperse, puede que le descubran y le expulsen de su cargo, perdiendo su empleo, los ingresos que éste le proporcionan y, si la tuviere, su buena reputación profesional. Es, pues, una valoración difícil de cuantificar pero real y el concepto de coste de oportunidad resulta adecuado para interpretar esta relación subjetiva entre coste y valor (Von Hayek, 1956: 527). Aunque es un concepto habitualmente empleado en asuntos de equilibrio estático, nosotros lo consideraremos en sentido dinámico; por ejemplo, si una empresa corrompe a un cargo público para conseguir la adjudicación de una contrata pública y es descubierta, a partir de ese momento podrían cerrarle las puertas de la Administración a nuevas licitaciones y ayudas públicas, de forma que lo que perdería es todo un flujo de ingresos futuros. La primera forma de intentar desincentivar al delincuente es incrementar este coste de oportunidad y una propuesta típica es aumentar el salario de los funcionarios y cargos públicos (Ades y Di Tella, 1997; Aidt, 2003; Kaufmann, 1997; Tanzi, 1998). Las dos siguientes maneras se refieren al beneficio extra que se obtiene gracias al acto corrupto. Lo descomponemos en ingreso y gastos.

B: $\downarrow$ Ingresos. El ingreso extra es la diferencia entre el ingreso esperado siendo corrupto y el ingreso obtenido no siéndolo. Ya no se trata de una valoración subjetiva sino que es el precio de un bolso, el sobrecoste de una obra pública o las mejoras que implica pasar de un contrato de personal eventual a laboral. Pueden cuantificarse. Las soluciones propuestas se centran en reducir ese plus de ingresos y el consejo típico es incrementar el grado de competencia entre los proveedores del sector público, que reduciría el margen de beneficio a obtener y, por tanto, el aliciente a corromper (Ades y Di Tella, 1997; Aidt, 2003; Bardhan, 1997).

C: $\uparrow$ Costes. El coste por corrupción se refiere a gastos de ocultación y protección que también se pueden cuantificar. Por ejemplo, mantener la fidelidad de un testaferro, asesoramiento de expertos en ingeniería financiera para crear empresas pantalla, servicios de abogados defensores e incluso favores a algún juez/a. Por supuesto, las recomendaciones van en sentido de aumentar este coste (Gray y Kaufmann, 1998). Si forzamos más trasparencia, por ejemplo, obligando a los cargos públicos (y sus familiares) a declarar su patrimonio y sus conflictos de intereses, aumentaría el coste de ocultación. Si establecemos responsabilidades subsidiarias para quien colabore en el acto corrupto, por ejemplo a los bancos con cuentas opacas, éstos trasladarían el valor de ese riesgo al precio que cobraría por ese servicio. 
D: $\uparrow$ Sanción. Los ingresos y los costes son ciertos, cosa que no ocurre con la sanción, aunque esté cuantificada. Por ejemplo, el nombramiento ilegal de un cargo público está castigado con "penas de multa de tres a ocho meses y suspensión de empleo o cargo público por tiempo de uno a tres años" (BOE, 2016, CP, Art. 405). Pero sólo se pagará si el delincuente es finalmente condenado y cumple la condena, y esto es lo incierto. Desglosamos esta magnitud en dos componentes, la severidad de la pena (que está determinada) y la probabilidad de cumplir condena (incierta). Esta última componente la desarrollaremos más adelante, cuando nos refiramos a los guardianes. Respecto a la sanción, se apuesta por incrementarla apoyándose en un planteamiento clásico, tanto desde la perspectiva penal (Beccaria, 2014 y Bentham, 1965) como de la económica (Becker, 1968; Jain, 1998), que insiste en que la severidad de la pena debe ser suficiente para disuadir (aunque no vengativa): "sanciones eficaces, proporcionadas y disuasorias de naturaleza penal o no penal, incluidas las sanciones pecuniarias" (BOE, 2010, Artículo 19.2).

\section{4.- Guardianes (capaces)}

Quiénes son. Los guardianes son todos aquellos agentes (y sus procedimientos) que desincentivan la comisión del delito potencial. Su naturaleza y función puede ser muy variada. El Diagrama 2 nos ayuda a apreciar esta diversidad.

\section{Diagrama 2. La cadena de prevención mediante (des)incentivación}

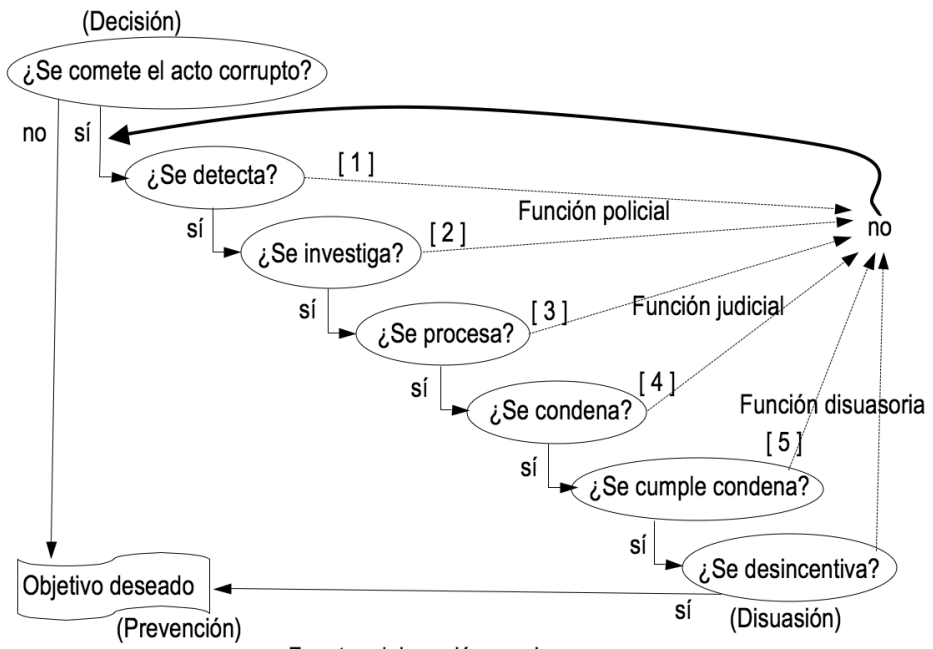


Un delincuente en potencia se planteará si vale la pena caer en la tentación. Si no lo hace es porque no quiere, no sabe o no puede. En el primer caso no es necesario desincentivarlo, pues respeta un código ético que es suficiente. En los otros dos casos hay que evitar que caiga en la tentación. Si suponemos que es racional (aunque no tenga muchas luces ni experiencia) se planteará el riesgo al que se somete: cumplir una condena (que puede conllevar varias sanciones). Para ello deberá ser [ 1 ] detectado, [ 2 ] investigado y detenido, [ 3 ] procesado, [ 4 ] condenado y, además, [ 5 ] deberá cumplir la condena. Si todo esto se cumple, no debería caer en la tentación. Esta es la función más importante del guardián: evitar el daño antes de que ocurra y, por encima de todo, impedir la entrada en el "círculo vicioso de la corrupción" (Villoria, 2006: 279-280).

Según el esquema anterior podemos distinguir tres tipos de guardianes. Los policías se encargan de detectar el delito, investigarlo y detener a los presuntos delincuentes. Después intervienen los jueces, que los procesan y condenan. El tercer grupo es el de los vigilantes, que se encargan de que la condena se cumpla y también de divulgar todo el proceso. Tres observaciones respecto a esta partición. Primera, su finalidad es analítica, en la realidad las funciones se pueden solapar; por ejemplo, la policía judicial es en parte policía pero depende del juez. Segunda, el nombre que les hemos puesto no es técnicamente preciso, por ejemplo, un civil que denuncia un acto corrupto en su empresa no es un auténtico policía pero cumple la función de detección. Y tercera, el último grupo a menudo se omite, sin embargo, su función como guardián es muy importante respecto a la desincentivación; por ejemplo, cuando las autoridades penitenciarias deniegan (justificadamente) el tercer grado a un preso y cuando la prensa informa del ingreso en prisión de un corrupto reafirman la percepción de "tolerancia cero".

Soluciones. El aparato del Estado posee guardianes para defenderse, pero no son infalibles (Antuñano, 2017). Cuantos más fallos, menos desincentivos y más riesgo de corrupción; entonces la sensación de impunidad puede estar servida. Se trata, pues, de no llegar a esa situación, corrigiendo esos fallos de dos maneras principales: más guardianes y más capaces. Para que haya más guardianes, se aumenta la cantidad de guardianes ya existentes y/o se incorporan nuevos tipos. Para que estén mejor capacitados se actúa sobre su eficacia/eficiencia (ver Diagrama 1).

E: $\uparrow$ más / nuevos. Cuando el problema es que hay insuficiencia de guardianes surge la duda de cuántos hacen falta, cuál es la "masa crítica" adecuada. Dedicar demasiados recursos públicos puede ser un derroche, quedarse corto también pues la corrupción los malversa. Hay mucha literatura sobre la existencia de ese "óptimo", tanto teórica como empírica, pero nada concluyente. En todo caso, recordemos que nuestro objetivo no es valorar las propuestas, tan sólo ordenarlas. Por supuesto, se reclama mayor dotación de personal especializado para la UCO, la UDEF, la Agencia Tributaria, los Tribunales de Cuentas o las fiscalías anticorrupción. Pero también mayor dotación presupuestaria destinada a material y equipos necesarios para que puedan hacer bien su trabajo. Al respecto, Garzón (2016: 135138) describe con claridad hasta qué punto llegaba esta "penuria" en el Juzgado Central 5 en los años noventa, en el que se procesaron los primeros grandes casos de corrupción postfranquista y en la que el personal del juzgado aportaba dinero de sus bolsillos para suplirla. Pero se puede aumentar la 
cantidad sin grandes esfuerzos presupuestarios. Por ejemplo, dotando a los guardianes con el patrimonio intervenido a los delincuentes (Rodríguez, 2016) o garantizando la protección a denunciantes, testigos y arrepentidos mediante leyes especiales (BOE, 2010, Art. 22), así se aprovecharía un potencial de guardianes "en reserva", dispuestos pero que no actúan por temor a represalias.

La corrupción evoluciona, su conocimiento también y, a partir de éste, surgen propuestas que aconsejan nuevos tipos de guardianes, tanto públicos como privados. La más recurrente es la creación de agencias anticorrupción especializadas, independientes, sin estar sometidas a ninguna presión ilícita, con formación y recursos financieros adecuados para sus funciones y obligadas a atender las denuncias presentadas, que no se limiten a ser "fachadas" de buenas intenciones (Tanzi, 1998; TIE, 2012: 347; Lagunes y Huang, 2015; Moene y Søreide, 2015; Ponce, 2016). También se proponen departamentos de empresa especializados en el control de riesgos de corrupción, sometidos a auditoria, bajo supervisión y responsabilidad de los administradores y acorde con criterios de "responsabilidad corporativa" (Boehm y Lambsdorff, 2009; Bacigalupo, 2016; Algaba, 2016). Otras propuestas son: comisiones electorales que controlen las donaciones a los partidos, defensores del pueblo locales con algún control sobre la burocracia y comités de vigilancia de ciudadanos que controlen las compras y licitaciones públicas (Bardhan, 1997), e incluso los obsequios "no simbólicos" recibidos por las instituciones (Garzón, 2015). Un último ejemplo: agentes especiales para vigilar las privatizaciones (aunque esta propuesta puede que llegue tarde) y para evitar la "captura del regulador" en organismos como la CNMV, el Banco de España o la CNC (Kaufmann, 1997; Gray y Kaufmann, 1998; Boehm, 2005).

A medio camino entre más guardianes y nuevos guardianes, se recomiendan cambios en los ya existentes, que los convertirían en "otros" más independientes y capacitados. Por ejemplo, respecto a la Oficina de Conflicto de Intereses se recomienda reforzar su independencia respecto del Ejecutivo, su autonomía para investigar y sancionar y la protección de su responsable, que sólo podría ser cesado por causas tasadas de remoción (CE, 2014; Betancor, 2016). Respecto a los tribunales de cuentas, mayor capacidad para hacer controles sistemáticos de todo aquel que reciba dinero público, más independencia y poder para sancionar económicamente (CE, 2014). Algunos proponen exigir a los jueces algún tipo de responsabilidad política, de modo que su legitimidad provenga tanto de su estatuto de funcionario como de su comportamiento ante los votantes, aunque Auger (1997) advierte de que éste es un debate delicado. Otros argumentan que al implicar a varios funcionarios en una misma jurisdicción, hacerlos trabajar en equipos o en parejas, evitaría los vis-a-vis corruptor-corrupto y el corruptor necesitaría corromperlos a todos ellos (Bardhan, 1997). También se plantea que los fiscales tengan autoridad directa y exclusiva sobre unidades policiales especializadas y que la Agencia Tributaria tenga una "policía fiscal" integrada con unidades especializadas de la Policía Nacional, de la Guardia Civil y de las Unidades Operativas de Vigilancia Aduanera, que mantendrían su dependencia orgánica pero actuarían bajo la dependencia funcional de la Oficina Nacional Antifraude (Garzón, 2015).

Como se ha indicado, para que los guardianes sean más "capaces" hay que actuar sobre su eficacia/eficiencia. Una queja reiterada desde distintos órganos es la escasez de recursos humanos, materiales, formativos, organizativos, procedimentales..., que limita los resultados obtenidos en su 
labor. Suponemos que se resuelven estas carencias y ordenamos las propuestas según sobre qué tipo de eficacia se centren (aunque existen vasos comunicantes entre las tres esferas que pueden generar sinergias).

F: $\uparrow$ eficacia policial. Para mejorar las funciones de detección-investigación-detención las propuestas clásicas son aumentar la probabilidad de detección con más controles regulares (CartierBresson, 1997), sorprender con auditorías aleatorias (como hicieron en el departamento de finanzas de Nueva York tras el escándalo de evasión fiscal de 2002; Lagunes y Huang, 2015) y extenderlas a los propios guardianes a modo de departamento de "asuntos internos" (Tanzi, 1998). Otra, también clásica pero modernizada, es potenciar las denuncias de testigos casuales, de víctimas (empleados, administradores, clientes, proveedores, competidores) y de los propios corruptos (que también son capaces de traicionar a sus compinches, según el principio de "pie invisible" de Lambsdorff, 2007). Para ello se desarrollarían sistemas de denuncias, bien anónimas bien confidenciales (Bacigalupo, 2016), confiables y accesibles incluso a través de Internet (Bardhan, 1997), que potencia el ciber-activismo anticorrupción (Hualing, 2015). Algunos proponen complementarlos con normas de indulgencia para la auto-denuncia en lugar de "tolerancia cero", pues ésta desincentiva a los arrepentidos (Boehm y Lambsdorff, 2009). Por supuesto, se insiste en la cooperación entre autoridades nacionales (UCO, UDEF...) y entre agencias internacionales (GRECO, Europol, GAFI...), que permitiría asistencia mutua, compartir información y agilizar la extradición tal y como recomienda Naciones Unidas (BOE, 2010), para que estos organismos no se limiten a ser "tigres sin dientes" (Boehm y Lambsdorff, 2009). Un último grupo de ejemplos se refieren a procedimientos más específicos: protección especial frente a ceses injustificados de agentes de órganos anticorrupción (TIE, 2012); incorporar en los expedientes urbanísticos la historia registral de las transacciones del suelo afectado (Garzón, 2015); mecanismos eficaces de verificación de patrimonios y de conflictos de interés de cargos públicos (CE, 2014); digitalización documental y registro informático interconectado entre juzgados y policías a nivel de Unión Europea (UE) (Garzón, 2015); creación de un registro público de "lobbies" en el que consten los presupuestos y gastos que han efectuado, las actas de sus reuniones con funcionarios públicos (y las agendas de los cargos públicos para cotejarlas con las actas), la documentación empleada en ellas y otros tipos de información relevantes para desentrañar cómo se han tomado determinadas decisiones (TIE, 2012:135; Brandt y Svendsen, 2016).

G: $\uparrow$ eficacia judicial. Las propuestas para mejorar la eficacia del procesamiento-condena son bastante similares a las anteriores en su esencia, pero su forma se adapta a los procedimientos propios del Poder Judicial. Conviene advertir que estos procedimientos se solapan con los policiales a pesar de que son guardianes que dependen orgánicamente de poderes diferentes y esto provoca algunos conflictos de competencias para los cuales también hay propuestas específicas. Respecto a las medidas compartidas con la eficiencia policial destacan: mayor dotación de recursos, programas formativos de especialización y reciclaje profesional; adopción de nuevas tecnologías para el acceso a bases de datos y digitalización de documentos para agilizar los procesos judiciales y mejor conexión con el ámbito policial y entre los distintos niveles jurisdiccionales; normas que protejan a denunciantes, testigos y arrepentidos; normas que regulen las obligaciones, responsabilidades y causas de cese 
de fiscales y jueces para garantizar su independencia del gobierno; y otras ya expuestas anteriormente. Respecto a las más específicas de este ámbito, el primer grupo destacable se refiere a la tipificación de los delitos (la "letra de la ley"), bien para convertir la para-corrupción en corrupción tipificada, bien para incluir en lo penal (que tiene un régimen sancionador más severo y estricto) delitos que ahora no lo están, aunque con precaución: "Las propuestas de los diferentes partidos políticos (en España) son muy variadas y tanta profusión de normas nos puede asfixiar" (Garzón, 2015: 471). Al respecto, aunque aún no se ha regulado correctamente el propio delito de corrupción (que aún no existe como tal), la reforma de 2015 del Código Penal (BOE, 2015) ha revisado al alza las penas y los tiempos de prescripción de los delitos y ha tipificado algunos como, por ejemplo, el soborno para obtener ventajas competitivas, la omisión o falsedad contable de partidos políticos y cargos públicos y la financiación ilegal de los partidos políticos, responsabilizando penalmente a aquellos que los financian, aunque su concreción técnico jurídica adolece de defectos formales y de fondo (Rasillo, 2016). Indicar que algunas tan sólo implican trasponer a la legislación nacional las leyes penales sobre corrupción de la UE ya ratificadas, es decir, se reclama mayor rapidez y respeto por el "espíritu de la ley". Hay un tercer grupo de medidas centradas en corregir o mejorar los procedimientos. Por ejemplo, respecto a los jueces se proponen cambios en los exámenes de acceso (que ahora pueden ser excesivamente memorísticos). Respecto a las fiscalías y fiscales anticorrupción: que tengan un plan de actuación, que la instrucción penal se les otorgue a ellos en lugar de a los jueces y que las investigaciones iniciadas por la fiscalía anticorrupción no puedan abortarse o impedirse por orden superior. Para descongestionar los juzgados se propone recurrir a la mediación, la conciliación y el arbitraje. También se propone revisar la Ley de Enjuiciamiento Criminal para evitar que se aproveche para bloquear y dificultar la investigación con trucos legales pero tramposos (como abusar de recursos a las sentencias, cambios injustificados de jueces y fiscales en pleno proceso y prácticas dilatorias que consiguen que los delitos prescriban). Además, se propone la eliminación de todos los aforamientos 0 , cuanto menos, su suspensión cautelar por resolución judicial si procede (Garzón, 2015).

H: $\uparrow$ eficacia disuasoria. Para que el efecto disuasivo de la sanción no se diluya, la gente debe tener la certeza de que las condenas sentenciadas por los jueces son firmes (no se reducen a posteriori) y que efectivamente se cumplen (Tanzi, 1998). Para que sea así, hay propuestas variadas. Los medios de comunicación, considerados uno de los guardianes más potentes detectando e investigando, son también los mayores divulgadores de imputaciones, registros, declaraciones, sentencias, entradas y salidas de prisión, indultos y demás pormenores del proceso policial-judicial. Cabe esperar que, si los medios no están corrompidos (Artero, 2016), cumplan bien está función y se propone la máxima libertad de prensa posible (algunos matizan que hay que encontrar un equilibrio entre el derecho a la información y las garantías procesales que evite los juicios paralelos). Por su parte, Garzón (2015: 471) considera que hay que revisar el tema de los indultos: "Después de 145 años de vigencia, la ley debe ser modificada. Con carácter general, creo que los delitos de corrupción no deben indultarse y, desde luego, debe ser una decisión fuera de la discrecionalidad del Gobierno". Hay un grupo de propuestas orientadas a que las penas no se diluyan. Una es exigir que para salir de prisión se haya devuelto el dinero defraudado. Otra es revisar los criterios de actuación de la Oficina de Gestión y Recuperación de Activos derivados del delito para que sea más eficaz y rápida, y así, reducir la sen- 
sación de que lo acumulado ilegalmente está a salvo de la ley (algo así como "me meterás en la cárcel unos meses, pero no me puedes tocar la fortuna que he acumulado"). También se propone modificar el artículo 305 del Código Penal, que genera dos perversiones; la primera es que, bajo ciertas condiciones, una regularización fiscal de lo defraudado permite reducir los grados de la pena; la segunda es que la regularización impide que se persigan por la vía penal la falsedad documental y contable vinculada a ese fraude concreto; es decir, que pagar a tiempo una multa a Hacienda permite reducir la pena e incluso eludir la cárcel (Garzón, 2015). Un último ejemplo es la adopción de medidas de transparencia de las decisiones judiciales durante el proceso, para que los abogados y los litigantes sepan por qué hay demoras (que podrían provocar la prescripción de delitos). Para finalizar con este territorio, indicar que muchas de estas medidas se solapan con las adoptadas para aumentar el coste de oportunidad del delincuente, ya que ambas tienen un efecto disuasivo.

\section{5.- Escenarios}

Qué son. Los escenarios son los espacios en los que interactúan víctimas, delincuentes y guardianes. Es más que un espacio físico, es sobre todo relacional, es decir, incluye a los actores y a las rutinas (formales e informales) a través de las cuales éstos interactúan. Es, por ejemplo, el hemiciclo del Parlamento, más los parlamentarios, más las formas parlamentarias (tanto las reglamentadas, como las conversaciones de pasillo). En nuestro caso el escenario es el de las políticas públicas.

En una democracia avanzada las políticas ejecutadas por los gobiernos deben reflejar fielmente la voluntad de los votantes. Si es así, el sistema es obediente, entendiendo que obediencia significa que la voluntad democrática se refleja en las decisiones gubernamentales y éstas se respetan y se realizan. Medellín (2004) delimita tres tipos de regímenes políticos de obediencia combinando "territorialidad" e "institucionalización del orden" (Tabla 1). La territorialidad completa se da cuando la acción del Estado llega a toda su jurisdicción. Institucionalización del orden plena significa que la acción del Estado es conocida, aceptada y practicada por toda la sociedad. La corrupción reduce el grado de obediencia, es una fuente de fragilidad institucional.

\section{Tabla 1. Regímenes políticos de obediencia}

\begin{tabular}{|l|ccc|}
\hline & Territorialidad & Institucionalización & Ejemplos \\
\hline I Sólidas & Completa & Plena & EUA, Francia, España \\
II Porosas & Completa & Incompleta & Argentina, Chile, Italia \\
III Endebles & Parcial & Incompleta & Colombia, México, Bolivia \\
\hline
\end{tabular}

FUENTE: Medellín (2004:23-24). 
Nótese que, según Medellín (quien a su vez, se apoya en Gomà y Subirats, 1998), el régimen de obediencia español es sólido. Aquí mantenemos que no es tan sólido y que nuestras diferencias con Italia (por ejemplo), no son tantas. Puede que hasta los años noventa la España posfranquista tendiese a normalizarse respecto a los patrones institucionales europeos, pero en algún momento se inició una involución que hizo que se mantuvieran (o recuperasen) rasgos de "porosidad", generando "una democracia no habitada por demócratas" (Pradera, 2014: 13).

Las políticas públicas se pueden representar como un ciclo político, que es la historia de cada política y como cualquier historia se puede contar de distintas formas. Una es el relato lógico, es decir, ordenar los acontecimientos según un esquema de referencia de cómo debería ser o haber sido (normativo); la otra es relatar los acontecimientos tal y cómo han ocurrido (empírico). Esta última modalidad es mucho más difícil, ya que la historia verdadera es esquiva y no respeta el esquema lógico-normativo. Si además parte de dichos acontecimientos son actos públicos corruptos, se ocultarán, deformarán o maquillarán como es inevitable en un mercado de limones.

\section{Tabla 2. Ciclo (morfogénesis) de las políticas públicas}

\begin{tabular}{|c|c|c|c|}
\hline & Propuesta A & Propuesta B & \\
\hline \multirow{2}{*}{1} & (Re)Surgimiento del problema & Situación detonante & \multirow{2}{*}{1} \\
\hline & Percepción del problema & Evento focalizador | Ventana de oportunidades & \\
\hline \multirow{2}{*}{2} & \multirow{2}{*}{ Inclusión en la agenda política } & Definición de agenda gubernativa & \multirow{2}{*}{2} \\
\hline & & Agentes y agencias $\mid$ Rutinas organizativas & \\
\hline \multirow{3}{*}{3} & Formulación de alternativas & Acuerdos (políticos) & 3 \\
\hline & Toma de decisiones & Toma de decisiones & 4 \\
\hline & Adopción de políticas & Enunciados de políticas & 5 \\
\hline \multirow{3}{*}{4} & \multirow{2}{*}{ Implementación de planes } & Definición de la agenda operativa & \multirow{2}{*}{6} \\
\hline & & Operadores $\mid$ Agencias operacionales & \\
\hline & Implementación de acciones & Despliegue territorial & 7 \\
\hline 5 & Evaluación de la intervención & & \\
\hline
\end{tabular}

FUENTE: Subirats, Knoepfel, Larrue y Varone (2012) y Medellín (2004).

La Tabla 2 sintetiza dos representaciones del ciclo. La primera (Propuesta A) pretende analizar las políticas en el seno de la Unión Europea, trascendiendo "los marcos nacionales tradicionales" (Subirats, Knoepfel, Larrue y Varone, 2012: 5). La segunda (Propuesta B) plantea dicho análisis en el seno de países de frágil institucionalización, es decir, "en condiciones de precariedad política e informalidad institucional" (Medellín, 2004: 5). Consideramos que A y B son representaciones compatibles, el esqueleto del ciclo es el mismo, aunque en cada una de las propuestas se enfatizan más unos u otros aspectos. Se trata de una esquematización de cómo surgen, se desarrollan y ejecutan (y evalúan, en su caso) las políticas. Nos sirve para comprender la morfogénesis de las intervenciones públicas, tanto su origen como la forma que van adoptando a lo largo del proceso político-administrativo. 
El ciclo se descompone en fases, cinco en la Propuesta A, siete en la B. Nosotros las integramos según muestra la Tabla 2 (conviene indicar que el ciclo puede ir hacia atrás, es decir, puede tener momentos de retorno a fases anteriores). Todas ellas corren peligro de corromperse, es decir, desviarse desde lo que debería ser.

La situación detonante [1] es cuando surge un problema preocupante (o una ventana de oportunidades a aprovechar) y adquiere tal relevancia social que pasa a ser un asunto público y, posteriormente, político. Entonces se incluye en la agenda gubernativa [2] y comienzan los conflictos, la toma de posiciones y los tira y afloja entre las fuerzas sociales. Si se llega a un acuerdo (o sin él, si hay suficiente mayoría), se toman decisiones que se plasman en [3] enunciados políticos (leyes, decretos, programas, planes...). Estas tres primeras fases tienen una naturaleza más socio-política; es donde la cultura, las instituciones y la praxis política tienen más peso. Por esa razón el poder judicial debe mantenerse al margen, siguiendo una especie de "principio de no injerencia" en los asuntos de los "policy makers" para evitar la "judicialización de la política" (Mena, 2010: 38-39), y por eso aquí predomina lo que hemos denominado para-corrupción, las "malas maneras" (a)legales no tipificadas como actos corruptos. No obstante, el paso del tiempo puede trasladar esas conductas desde lo legal hasta el delito tipificado, ya que, como indica Ruiz-Funes (2013: 266), "toda norma jurídica está precedida de una norma de cultura y tiene una causalidad que varía de acuerdo con el cambio de las situaciones sociales"; por ejemplo, en su día la Ley de Financiación de partidos políticos y más reciente la Ley de Transparencia.

Para identificar las desviaciones de lo hecho (empírico) respecto del buen hacer (normativo) las cuestiones clave en este grupo de fases son: ¿cómo se ha tomado conciencia del problema (o de la oportunidad)? ¿qué factores han llevado al gobierno a actuar (o no) ante el problema? ¿qué soluciones se han propuesto y cuáles se han aceptado por parte del Gobierno y del Parlamento? y ¿qué procesos se han seguido para formular dichas soluciones? Veamos algunos ejemplos de cómo se pueden para-corromper estas fases.

Respecto a la primera fase, la actitud de los medios de comunicación (el gran guardián) puede tergiversar, exagerar e interpretar sesgadamente los hechos e incluso inventarlos o intentar ocultarlos. Los motivos pueden ser ideológicos, económicos, políticos e incluso personales. Respecto a la "exageración", Garzón (2016: 847) describe cómo la cacería a la que asistió en 2009, "un hecho absolutamente inocuo" le costó el puesto al Ministro de Justicia y a él su inhabilitación. Respecto a la "invención", se pueden lanzar campañas institucionales mostrando un futuro idílico si se construyen con dinero público Ciudades de la Luz, de las Artes Escénicas... e incluso la Ciudad de la Euforia, hasta el punto de convertir en interés general "fantasías públicas" que nadie había reclamado (Serna, 2013: 72). Respecto a la "ocultación", recientemente el documental de investigación "La estrategia del silencio" (Peris, 2017) nos ha mostrado cómo se puede ocultar un grave asunto de auténtico interés social durante años: el accidente del metro de Valencia. El control que el gobierno tuvo sobre los principales guardianes implicados (RTVV, trabajadores de Metrovalencia, peritos e incluso instancias judiciales) fue prácticamente completo y logró no sólo que el asunto no entrara en la agenda política, sino 
que "no existiera" en la memoria colectiva de la población (Salvados, 2013). Pero la prensa no es la única implicada en la creación de opinión: una patronal puede colaborar financieramente (o no) con una fundación sin ánimo de lucro que publica informes que defienden reformas laborales y una gran empresa energética puede encargar un estudio académico que respalde (con mayor o menor rigurosidad científica) la necesidad de introducir o eliminar subvenciones a determinadas energías (desde 1975 el fraude científico se ha multiplicado por diez, Europa Press, 2012). Todo esto influye en la percepción general del problema y de su relevancia (Uriarte, 2002).

Respecto a los procesos que se siguen para formular y adoptar soluciones, la manera en que se aprobaron los Presupuestos Generales del Estado de 2017 en el Parlamento podría considerarse un ejemplo ilustrativo de "malas maneras". Se presentaron siete enmiendas a la totalidad por parte de la oposición parlamentaria. El Gobierno necesitaba los 175 votos necesarios para que el empate técnico anulara las enmiendas a la totalidad. El apoyo del PNV era el único que no estaba seguro y comenzó una negociación. Consiguió sus votos a cambio de mejoras en las condiciones del Concierto Económico y promesas de inversiones en infraestructuras. Si el Gobierno lograba un voto más, se liberaba del resto de enmiendas (más de cinco mil). Consiguió el voto del diputado de Nueva Canarias (que fue electo en coalición con el PSOE-Las Palmas y que también había presentado enmienda a la totalidad) a cambio de unos cientos de millones de euros para Canarias. Es incuestionable que el Parlamento es un órgano soberano y los parlamentarios pueden hacer con sus votos lo que quieran (o lo que su partido quiera), pero sería conveniente evitar la excesiva laxitud ética y salvaguardar su reputación, como en Inglaterra, por ejemplo, donde se recurrió a procedimientos de autorregulación política que evitan injerencias en la soberanía parlamentaria (Oliver, 1997).

Respecto a la fase 3, la amnistía fiscal contemplada en el Real Decreto-Ley 12/2012 es un ejemplo ilustrativo de "malos" procedimientos. En 2017 el Pleno del Tribunal Constitucional (TC) anuló por unanimidad dicha amnistía fiscal porque el decreto-ley no es el vehículo normativo adecuado para esta decisión. No obstante, avaló las declaraciones de los que se acogieron, algunos de ellos procesados por corrupción. Aunque el TC consideró que implicaba una "abdicación del Estado" de sus obligaciones, el Ministro de Hacienda consideró que tan sólo se trató de una "descalificación por el procedimiento". Cabe indicar que, además de su ineficacia recaudatoria, es una medida incentivadora de malas maneras, ya que no sólo redujo el tipo de gravamen, sino que también exoneraba de recargos y sanciones penales y administrativas (si el origen de los fondos era de procedencia lícita), es decir, supuso en la práctica "legitimar" el fraude fiscal. También cabe indicar que se trata de una sentencia con más trascendencia política que jurídica, es decir, "judicializa la política"; no obstante, algunos consideran que los jueces y las cortes constitucionales son "guardianes del pacto orginal" entre los representados y sus representantes y de los derechos fundamentales de los ciudadanos (Wildemeersch, 2016).

En la fase 4 se establecen los aspectos concretos en la agenda operativa (quién llevará a cabo cada acto de implementación, cuándo, cómo...), se pone en marcha la maquinaria y tiene lugar el despliegue territorial de las políticas. Aquí las cuestiones clave son ¿se han aplicado las decisiones del 
Gobierno y del Parlamento? y ¿cómo se han aplicado? Si en la formación de la política (fases 1, 2 y 3) predomina el régimen político (las actuaciones socio-políticas), en ésta predomina el aparato estatal (las actuaciones burocrático-administrativas). Las primeras se desarrollaron en la arena política, donde casi todo vale. Pero la implementación se realiza a través de los agentes y agencias públicas 0, si se prefiere, actores-red (Grau, íniguez-Rueda y Subirats, 2010), sometidos a estructuras y rutinas organizativas y a procedimientos explícitos y reglamentados que deben respetarse, so pena de cometer delitos. Esta es la "suprema regla" de la buena gestión burocrática (von Mises, 2005) y, si no se respeta, el poder judicial sí puede intervenir, por eso aquí es donde se concentra el grueso de la corrupción tipificada. Ya se han mostrado ejemplos al respecto y no procede insistir más en ello.

Cabría esperar una última fase de evaluación [5] de cómo ha ido la cosa, respondiendo a la pregunta: ¿cuáles han sido los efectos directos e indirectos de la política? Ésta debería mostrarnos los errores cometidos por las políticas públicas realizadas para intentar no tropezar dos veces con la misma piedra (también los aciertos). Debería ser así y en algunos países se hace, en otros ni se plantea y en otros hay voluntad de hacerlo, pero es una voluntad muy débil; este último es el caso español. En 2006 se oficializó la creación de la Agencia Estatal de Evaluación de las Políticas Públicas y la Calidad de los Servicios, pero su actividad evaluadora es muy escasa e incluso, diez años después, su "Eje Estratégico primero" sigue siendo "Crear Agencia" (AEVAL, 2016). Volveremos más adelante sobre este asunto cuando planteemos la necesidad de los "compromisos explícitos" (y vinculantes).

Soluciones. Para ordenar las propuestas anticorrupción en este territorio tenemos en cuenta tres componentes: los actores de las políticas públicas que se relacionan entre sí, los procedimientos mediante los cuales dan forma a dichas políticas y el escenario en el que lo hacen (ver Diagrama 1). Se puede intentar transformar una de estas componentes, dos o todas; en todo caso, un cambio en alguna de ellas generará readaptaciones más o menos espontáneas en las otras.

I: Mejorar escenario. ¿Cómo se puede modificar el contexto relacional de los actores para reducir el riesgo de corrupción? Una propuesta típica es la liberalización económica (privatizar, externalizar, desregular). El planteamiento es conocido: menos Estado, menos corrupción pública; y más competencia privada o privada-pública, menos corrupción (Bardhan, 1997; Boerner y Hainz, 2009). Aunque otros advierten que el "Estado mínimo" no es la solución (Jiménez de Parga, 1997). También se reclama más competencia democrática (Pradera, 1997); es otra propuesta tradicional centrada no tanto en el escenario económico, sino en su dimensión socio-política y se fundamenta en contrapesos eficaces (Shleifer y Vishny, 1993). Esto se puede concretar, por ejemplo, en cambios en las leyes electorales (ley D'hondt, por ejemplo) que permitan ir más allá de la alternancia bipartidista mediante una mayor presencia parlamentaria de partidos no mayoritarios. También se defienden medidas antimonopolio en el sector medios de comunicación (Garzón, 2015). Otras propuestas se orientan hacia la re-centralización de determinadas competencias desde municipios a gobiernos autonómicos y desde éstos al nivel estatal, por ejemplo, en materia de urbanismo y medioambiente (Iglesias, 2007). Esto se justifica en que en un Estado tan descentralizado como el español, los controles en los niveles inferiores son escasos o inexistentes (Jiménez Sánchez, 2008, Mir y Cruz, 2012). 
Un último ejemplo respecto a modificaciones en el escenario interno, es el de la reforma estructural de determinadas instituciones gubernamentales (Tanzi, 1998), incluso la clausura de algunas como el Senado y las Diputaciones Provinciales. Respecto al escenario global que envuelve el nacional, el hueso más difícil de roer es el de los "offshore", los paraísos fiscales (Alldridge, 2015). Las propuestas oscilan desde peticiones suaves de colaboración (casi súplicas) hasta la derogación del secreto bancario, acompañada de normas vinculantes (al menos en el seno de la UE) que obliguen a las empresas a facilitar información cualquiera que sea el país en que operen sus filiales y con sanciones para quien no colabore (Garzón, 2015). Además se reclama aplicar en el extranjero las legislaciones nacionales contra el soborno (como recomienda la OCDE) y que las instituciones internacionales prioricen la lucha contra la corrupción cuando presten asistencia a sus países miembros (Gray y Kaufmann, 1998). Indicar, por último, que también hay propuestas hacia lo local, por ejemplo, para concienciar y empoderar a las comunidades locales en asuntos medioambientales, ya que en algunos casos su proximidad las hace más eficaces que el aparato administrativo (Gore, Ratsimbazafy y Lute, 2013). Estas y otras transformaciones pretenden abrir y cerrar determinadas puertas a los actores y así modificar el modo en que se relacionan.

$\mathrm{J}$ : Mejorar actores. Cambiar a los actores significa básicamente transformar sus actitudes ante la corrupción. La mayoría de estas propuestas se vinculan directa o indirectamente a códigos deontológicos referidos "a la moral, es decir, a aquella parte del dominio de las acciones que no está bajo el imperio de la pública legislación" (Bentham, 1836: 19). Es, por tanto, una auto-reglamentación colegiada (semi)privada, que pretende depurar los comportamientos de un determinado colectivo (des)incentivando a sus propios miembros. El objetivo de estos códigos es regenerar la moral política y cívica (Soriano, 2011). Respecto a los políticos, estos códigos éticos deberían no sólo lograr la honradez de los gobernantes y líderes (Gray y Kaufmann, 1998), sino además hacerlos visiblemente activos e intolerantes con la corrupción, ya que el ejemplo proporcionado por el liderazgo es muy importante (Tanzi, 1998). Lo mismo reza para los parlamentarios y sus partidos, que deberían promover buenas prácticas, pactos de integridad y coaliciones anticorrupción (González de Asís, 2001; Arribas, 2016), tal y como recomienda el Parlamento Europeo en su Resolución de febrero de 2013 (CE, 2014). En el caso español, incluso se recomienda entrenamiento y asesoramiento ético (GRECO, 2016). Los códigos se pueden complementar con comités (externos) de moral pública en las instituciones (Soriano, 2011) y se extienden a los medios de comunicación y al ámbito empresarial. Este último es especialmente importante ya que su razón de ser, el beneficio propio, le hace más proclive a caer en la tentación, especialmente si practican la actividad de "lobbying". Al respecto se propone la elaboración de guías éticas y reglas de buena conducta, la implantación de políticas de Responsabilidad Social Corporativa y la promoción y motivación del comportamiento ético desde la alta gerencia (TIE, 2011, OCDE-UNODC-Banco Mundial, 2013; Bacigalupo, 2016). La "public compliance» (Queralt, 2016) es una propuesta recientemente materializada en la norma UNE 19601, que "establece unas directrices y requisitos mínimos para adoptar, implementar, mantener y mejorar políticas, procesos y sistemas de "compliance» penal que permitan reducir y mitigar el riesgo de comisión de ilícitos penales en el seno de las organizaciones y favorecer una cultura ética y de cumplimiento" (TIE, 2017). Además de estas optimistas recomendaciones, hay otro grupo de propuestas más concretas que afectan a cargos públi- 
cos y a algunas instituciones. Respecto a los primeros, se defiende: la profesionalización de los cargos técnicos, separando las carreras de políticos y funcionarios; que los dirigentes políticos tengan restringido y controlado el nombramiento y cambio de los empleados públicos; y limitar el número de asesores nombrados a dedo, que su elección se base en competencias, aptitudes y méritos (al estilo sueco o neozelandés) y con dedicación exclusiva (Tanzi, 1998; Lapuente, 2016). Respecto a cambios en las instituciones, Garzón (2015) propone: que el Consejo de Transparencia y Buen Gobierno no sea nombrado por el Gobierno; que el Tribunal Constitucional y el Tribunal Supremo se sometan a procesos de selección con participación ciudadana, con criterios de mérito y capacidad y corroborados por dos tercios de las dos cámaras; y que los veinte vocales del Consejo General del Poder Judicial sean elegidos por los ciudadanos.

K: Mejorar procedimiento. Los procedimientos delimitan lo que se puede hacer y lo que no se debe hacer. Su modificación mueve la frontera de la (a/i)legalidad. Un primer grupo de propuestas defienden eliminar determinadas regulaciones, sea porque son innecesarias, disfuncionales u opacas, sea porque implican tramitaciones complejas y lentas, sea porque otorgan demasiada discrecionalidad a quienes toman las decisiones (Kaufmann, 1997; Tanzi, 1998; Bardhan, 1997). Hay versiones más suaves que no proponen la eliminación total, sino su perfeccionamiento, ya que la desregulación puede ser peligrosa (Jiménez de Parga, 1997). En consecuencia, prefieren re-regular mediante codificaciones más detalladas y normas jurídicas limitadoras (que también reduzcan la discrecionalidad del funcionario en la toma de decisiones), así como flexibilizar trámites o suprimir requisitos superfluos en parcelas de menor riesgo (Jiménez de Parga, 1997; Soriano, 2011). En el sentido contrario, algunas propuestas defienden más intervención allí donde la regulación es escasa 0 inexistente, por ejemplo, algunas ya expuestas como la de los lobbies y en general de las empresas (mediante la UNE 19601). Otro grupo se centra en modificar procedimientos en puntos concretos donde el riesgo de corrupción es alto, especialmente en las adquisiciones, contrataciones y licitaciones públicas (Gimeno, 2016). Algunos ejemplos. Para poner "cortafuegos" entre demanda y oferta de sobornos se proponen: la contratación pública en línea ("e-procurement"), así los que compiten por un contrato no saben quiénes tomarán la decisión; más rotación del personal en posiciones vulnerables; y monitoreo expost por parte de grupos competidores (Boehm y Lambsdorff, 2009; RoseAckerman y Truex, 2012). Se propone también adoptar las nuevas TIC en la Administración, que permitirían simplificar y acelerar los trámites administrativos y facilitarían la rendición de cuentas y la alerta temprana de conflictos de intereses (Garzón, 2015; Lagunes y Huang, 2015). Otras son más específicas como: la prohibición de fraccionamientos injustificados de contratos, la paralización del procedimiento ante la existencia de informes no favorable o negativos, la regulación del régimen de subvenciones públicas y evaluaciones del riesgo de corrupción en administraciones regionales y locales (Garzón, 2015; Lapuente, 2016; CE, 2014). El último grupo de propuestas a considerar, pero quizás el más importante para nuestro interés, se orienta a mejorar la precisión de las políticas públicas (Cartier-Bresson, 1997). Principalmente se defiende la normalización de buenas prácticas a partir de experiencias exitosas (CE, 2014). A veces la clave del éxito se identifica con la introducción de técnicas de gestión privada en materia de planificación, administración financiera y presupuestaria, contabilidad y auditoría (Kaufmann, 1997). También en el sometimiento a evaluaciones independientes, 
especialmente de los grandes contratos de obras públicas y de las decisiones de planificación urbana (CE, 2014). Otros consideran que los programas electorales deberían ser como auténticos contratos de adhesión (López Álvarez, 2016). Al respecto, March (2017) defiende que las promesas de los políticos (recordemos que son el agente) sean un "compromiso explícito", detallado, preciso, público y sancionable a posteriori por parte de los votantes (el principal). Para ello se propone que sean las buenas prácticas que se les exigen a las ONG las que se extiendan a las OG (Organizaciones Gubernamentales, en sus distintos niveles) y que se creen órganos especiales para fiscalizar, evaluar (rendición de cuentas) y hacer públicas (transparencia) las desviaciones de las promesas respecto de los resultados reales.

\section{6.- Víctimas}

Obviamente las víctimas son todos los perjudicados por los actos corruptos. El "triángulo de los actores" (Subirats, Knoepfel, Larrue y Varone, 2012: 57) nos sirve para hacer un par de observaciones importantes. Nuestro problema es la corrupción y los grupos-objetivo (primer vértice del triángulo) son los actores cuyo comportamiento causa el problema, es decir, nuestros delincuentes. Los beneficiarios finales (segundo vértice) son los que sufren el problema, nuestras víctimas. La política anticorrupción es la intervención pública que pretende cambiar la forma de comportarse de los primeros para evitar los daños en los segundos. El tercer vértice del triángulo son los grupos terceros afectados indirectamente por la política. Si les afecta positivamente (por ejemplo, las empresas que quedan excluidas de las licitaciones públicas por la competencia desleal de los corruptores), cabe esperar que se posicionen a favor de las medidas anticorrupción. Si por el contrario les perjudica, cabe que se opongan (por ejemplo, lobbies que van a reducir su poder de influencia malsana por culpa de una mayor transparencia). Primera observación: las víctimas son más de las que parecen, por tanto, conviene adoptar una perspectiva de la "victimización" no estrecha y hacerla visible a las propias víctimas. Segunda observación: los intereses de los terceros afectados, si actúan como palanca de movilización, pueden alterar la correlación de poder entre los buenos y los malos, pasarían a ser una extensión de éstos; por tanto, la búsqueda activa de coaliciones por parte de las víctimas (y de los guardianes) es fundamental para el éxito de las políticas anticorrupción.

Para que las víctimas (directas e indirectas) actúen, han de disponer de tres cosas (March, 2015): (1) conocimiento de la corrupción, (2) capacidad para combatirla y (3) voluntad de hacerlo. Ordenaremos las propuestas de solución a partir de estas tres disponibilidades (ver Diagrama 1).

L: $\uparrow$ Saber (conocimiento). La primera condición necesaria para actuar contra la corrupción es conocer su existencia, su magnitud y las formas y modos que adopta. Sen (2000, 223-224) insistió en 
"el papel informativo de la democracia", en particular de la libertad de prensa. El grueso de este grupo de propuestas va en este sentido general, una prensa vigorosa e independiente respaldada con leyes de protección del secreto oficial menos estrictas, aunque también con protección ante la difamación (Bardhan, 1997, Rose-Ackerman y Truex, 2012). Las medidas se focalizan sobre distintos ámbitos según sea la preocupación específica del proponente: la actividad general de las entidades públicas (Bacigalupo, 2016), el proceso de toma de decisiones (CE, 2014), la documentación pública (Guichot, 2016), empresas, mercados y precios (para minimizar la captura del regulador) (Boehm, 2005; Kaufmann, 1997), donaciones, financiación de medios de comunicación... y algunas que ya han sido expuestas al referirnos a las leyes de transparencia y no cabe insistir más. Hay otras centradas, más que en generar información, en facilitar su difusión creando interfaces entre la sociedad civil y los actores estatales (McGee y Gaventa, 2011): bases de datos centralizadas accesibles online al público (en las que consten presupuestos, patrimonio público, sueldos, gastos relacionados con viajes, dietas, llamadas telefónicas, tarjetas...); publicidad activa a través de portales de transparencia (efectivos) y web informativas; facilitar la publicidad pasiva limitando las categorías de información restringida, que la solicitud se haga en los propios portales, con silencio administrativo positivo, que no tengan que estar motivadas y que no se exija identificación del solicitante para evitar coartar solicitudes por represalias (Guichot, 2016); y creación de consejos de transparencia (encargados de resolver reclamaciones contra aquellos sujetos obligados a transparencia cuando obstaculicen el acceso a la información), independientes, con personalidad jurídica propia y plena capacidad de actuar (Guichot, 2016). Un último grupo de ejemplos son las medidas orientadas a enseñar qué es corrupción: campañas de información-sensibilización, educación de la ciudadanía en esta materia e introducción de asignaturas y contenidos contra la corrupción en los distintos niveles educativos (respaldado por las actitudes en la familia), así como formación del profesorado en estas materias (incluyendo medidas contra la corrupción en el propio sector de la educación; TI, 2013).

M: $\uparrow$ Poder (capacidad). Saber no implica poder 0, en otras palabras, "la transparencia no necesariamente genera rendición de cuentas" (Fox, 2008: 198). Poder significa disponer de recursos materiales, humanos y especialmente institucionales para luchar contra la corrupción. Las principales propuestas orientadas a aumentar el poder de las víctimas potenciales apuestan por la misma orientación: más participación en todas las fases del ciclo de las políticas públicas. Las diferencias estriban en las características de dicha participación. Por supuesto se sigue valorando positivamente la participación a través de la representación delegada. Unos reivindican el papel tradicional de los partidos políticos pero re-conectados con la sociedad a través de sus militantes. Para ello consideran necesaria la democratización interna de los partidos (cambios organizativos, procedimentales y éticoideológicos, además de liberarlos del "yugo financiador") para que los militantes actúen como interfaz eficaz entre el pueblo y sus líderes (CE, 2014; López Álvarez, 2016; Pradera, 1997; Ridao, 2015). Otros apuestan por representaciones alternativas a la del filtro partidista. La figura estelar es el comité de participación ciudadana en aquellos espacios dónde se requiere su contrapeso "bottom-up" (Boehm, 2005, Rose-Ackerman y Truex, 2012), sea para averiguar, supervisar o tomar decisiones (Shah, 2007). Se trata de sacar el futuro "del confuso y oscuro ámbito de la alta política «anunciada en televisión" para bajarlo al nivel de la calle, las fábricas, las oficinas, los colegios y los espacios públicos donde 
nosotros, ciudadanos del pueblo llano, nos encontramos y conversamos" (Bauman, 2017: 160). Para intentar superar el problema de la agencia que implica la representación delegada, otra propuesta es la representación directa vía refrendos (a la manera suiza) para aquellas decisiones que claramente afectan al "interés general", por ejemplo, privatizar lo que es de todos (Garzón, 2015) y destacan las propuestas para más participación en los presupuestos públicos. Un último tipo de participación es el que podríamos denominar participación "líquida" (Bauman, 2002), ya que no se realiza a través de estructuras sólidas como el partido o el comité, ni implica a todos los votantes, sólo a aquellos que quieren participar activamente. En este caso, a partir de la experiencia reciente de diversas movilizaciones populares, la esperanza se deposita en el activismo a través de Internet (Sampedro et al, 2011; Castells, 2015). En todo caso, sea cual sea la modalidad de la participación, se aconseja la creación de coaliciones entre actores estatales reformadores (del ejecutivo, del judicial y del legislativo), aliados no estatales (como medios de comunicación y académicos) y, por supuesto, los ciudadanos (y sus organizaciones sociales), con el fin de alterar el equilibrio de poder entre defensores y detractores de la transparencia y la rendición de cuentas (McGee y Gaventa, 2011).

N: $\uparrow$ Querer (voluntad). Para Gramsci (2011) la indiferencia es el peso muerto de la historia. Efectivamente es un lastre para las fuerzas de la transformación, pero una aliada para las de la conservación. En medio están los indiferentes y las propuestas en este territorio insisten en que hay que sacarlos de ahí, pero no se les puede obligar. La mayoría son propuestas indefinidas en cuanto a los instrumentos y muy vagas en cuanto a los objetivos: implicar a los ciudadanos, concienciar y movilizar a la población, fomentar una cultura política de acción ciudadana en la esfera política, encontrar focos de apoyo político para crear voluntad política, establecer roles que motiven a los votantes a permanecer vigilantes e interesados en el resultado de las políticas públicas... (Gray y Kaufmann, 1998; Klitgaard, 1998; Cartier-Bresson, 1997). Una propuesta recurrente (sobre todo para países subdesarrollados y excomunistas) son las campañas anticorrupción periódicas, al estilo "Manos Limpias" italiano de los años noventa del siglo veinte, creíbles y sostenibles (Bardhan, 1997). Pero otros consideran que la evidencia muestra que "frecuentemente no sólo son ineficaces sino pueden incluso ser contraproducentes" (Holmes, 2007: 100). También hay quienes consideran que hay que aprovechar los escándalos de corrupción como catalizador del cambio político, como detonante de crisis que pueden generar cambios (Arroyo, 1997; Jiménez Sánchez, 1997; Jiménez de Parga, 1997), como ocurrió con el Caso Guerra cuya consecuencia fue la criminalización del delito de tráfico de influencias (Cartolano, 2012). Tanto las campañas anticorrupción como los escándalos tendrían una función de control social, las primeras de carácter sistemático y los segundos esporádicos. No obstante la posible catarsis, el castigo a la corrupción en las urnas es más la excepción que la norma general (Johnston, 2013; Artés y Jiménez Sánchez, 2017).

Se puede conseguir más conocimiento sobre corrupción ( $\uparrow$ saber) con medidas de trasparencia "T" y más capacidad de acción ( $\uparrow$ poder) con medidas de rendición de cuentas "R", pero nada garantiza que lo conseguido con "T+R" sea suficiente (McGee y Gaventa, 2011). Para convertir a un ciudadano indiferente en activista, previamente hay que concienciarlo y predisponerlo para la acción. Pero una vez logrado esto aparece de nuevo el problema del coste de oportunidad, en este caso de la víc- 
tima. La militancia activa implica dedicar recursos y sobre todo tiempo, que hay que sacarlos de otro lugar, por ejemplo, del ocio o del descanso. Si ello implica demasiado sobre-esfuerzo la inercia actúa paralizando la catarsis. Por esta razón los sindicatos disponen de la figura del "liberado". Pero fuera de algunos ámbitos laborales no existe, son los propios políticos los "liberados" que deberían asumir esta tarea y nótese que pueden coincidir en la misma persona (o partido político) los papeles de guardián y delincuente. De nuevo, el problema de la agencia, que nos vuelve a dejar en manos de la calidad personal del agente. No obstante esta dificultad, Fox (2007 y 2008) considera que hay alguna esperanza. Si algunos de estos agentes, como actores horizontales de rendición de cuentas capaces y eficaces, logran involucrar a movimientos sociales transformadores de muchas partes, se puede alcanzar una alianza con los ciudadanos que sea suficiente para alterar la correlación de fuerzas y lograr algún éxito parcial (el movimiento social actuaría como intermediario entre el agente y el principal, reduciendo el coste de oportunidad del ciudadano). Y dicho éxito parcial podría actuar como un signo positivo de progreso, reforzar un compromiso más profundo y sacar de su apalancamiento a más ciudadanos, es decir, se cumpliría la regla de oro del arte de la transformación (Matus, 1980: 284285): "El triángulo une-suma-avanza es de una lógica recurrente e implacable. Nos dice: «primero une tus propias fuerzas, luego suma 0 agrega nuevas fuerzas a tu propio objetivo y después avanza. Inmediatamente después del avance une nuevamente tus propias fuerzas"”. Es una vía lenta e incierta pero parece la única capaz de consolidar una cultura anticorrupción que persista más allá del escándalo político esporádico: "sin reformas que conduzcan a culturas políticas colectivas, puede ser casi imposible generar reglas de compromiso contra la corrupción" (Collier, 2002, 26). En suma, lograr la suficiente voluntad política de las víctimas sigue siendo el gran misterio sobre cómo se moviliza políticamente a las masas.

\section{7.- Recapitulación: ¿para qué puede servir este mapa?}

El objetivo de este trabajo ha sido proponer un mapa que permita tener una visión de conjunto de las propuestas anticorrupción existentes y de las que van surgiendo. Nos hemos apoyado en una combinación de la TER y la TAR para establecer los territorios de la corrupción y en ellos hemos ubicado, con carácter ilustrativo, algunas de las medidas propuestas. Más allá de este objetivo (a modo de posibles estudios y aplicaciones futuras), quizás sirva para otras cosas:

- Identificar territorios y parcelas que quedan desamparadas y otras que padecen sobrecargas. Por ejemplo, hay pocas propuestas concretas para aumentar la voluntad de las víctimas $[\mathrm{N}]$, pero muchas para reformar los procedimientos que se emplean en los escenarios de las políticas [K]. 
- Detectar incoherencias o incompatibilidades entre distintas propuestas. Por ejemplo, proponer reducir la financiación pública de los partidos políticos y al mismo tiempo intentar liberarlos del yugo de sus financiadores privados.

- Descubrir procesos de causación circulares y acumulativos, tanto viciosos como virtuosos (que son más malignos/benignos que los lineales). Ejemplo de vicioso: $\rightarrow$ guardianes poco dotados $\rightarrow$ más corrupción $\rightarrow$ menor relación dotación guardianes/corrupción $\rightarrow$ guardianes aún menos dotados. Ejemplo de virtuosos: la víctima sabe más $\rightarrow$ la víctima exige más anticorrupción $\rightarrow$ los políticos son más intolerantes con la corrupción $\rightarrow$ se dota más presupuesto público para guardianes $\rightarrow$ aumenta la transparencia $\rightarrow$ la víctima sabe más.

- Si los recursos que podemos dedicar a combatir la corrupción son limitados (que lo son), las circularidades anteriores ayudarían a encontrar dónde concentrarlos, a modo de estrategia de crecimiento desequilibrado (Hirschman, 1981). Por ejemplo, en lugar de crear nuevos guardianes dispersos en distintas parcelas y distribuir los recursos entre ellos, crear una agencia anticorrupción única (coordinadora de los guardianes ya existentes) que concentre los recursos y así logre alcanzar economías de escala y genere efectos arrastre en distintos territorios.

- Si algún día se proponen auténticos planes integrales anticorrupción, el mapa facilitaría su comparación. Permitiría contrastar qué espacios quedan más vacíos en cada uno de ellos y dónde hay sobrecargas. Esta comparación ayudaría a discutirlos con un "lenguaje común" y, quizás, a consensuarlos técnica y políticamente. Estas diferencias de "lenguaje" se aprecian claramente cuando se comparan las propuestas de juristas, economistas, politólogos y sociólogos.

- Por último, un mapa (sea este u otro) ayuda a localizar los "tiempos políticos". Cada medida anticorrupción necesita su tiempo de maduración y da frutos (o no) a partir de un determinado momento. Unas son más rápidas, otras son más lentas. Si queremos que dos medidas actúen simultáneamente sobre un mismo territorio, habrá que ajustar esa sincronía. De no ser así la más rápida puede fracasar, no porque sea incorrecta, sino porque la más lenta era también necesaria, pero llegó tarde.

El campo de batalla está servido. 


\section{8.- Bibliografía}

ADES, A. \& DI TELLA, R. (1997): "The New Economics of Corruption: a Survey and some New Results", Political Studies, 45: 496-515.

AEVAL (Agencia Estatal de Evaluación de las Políticas Públicas y la Calidad de los Servicios) (2016): Plan de Acción Anual 2016. Ministerio de Hacienda y Administraciones Públicas. (http://www.aeval.es/export/sites/aeval/comun/pdf/agencia/Plan_de_Accion_2016.pdf; extraído el 13/3/2017).

AIDT, T.S. (2003): "Economic Analysis of Corruption: A Survey", The Economic Journal, 113(491): 1-32. DOI: $10.1046 / j .0013-0133.2003 .00171 . x$

AKERLOF, G.A. (1970): "The Market for "Lemons": Quality Uncertainty and the Market Mechanism", The Quarterly Journal of Economics, 84(3): 488-500.

ALGABA GARRIDO, E. (2016): "Formación: la base de una cultura empresarial de cumplimiento", Revista Internacional de Transparencia e Integridad, 1. En: http://revistainternacionaltransparencia.org/wp-content/uploads/2016/09/EVA-ALGABA.pdf; extraído el 20/6/2017.

ALLDRIDGE, P. (2015): "Tax avoidance, tax evasion, money laundering and the problem of 'offshore". En: Rose-Ackerman \& Lagunes, 317-335.

ANTUÑANO MARURI, I. (2017): "Política económica y control del sector público". En: Mancha Navarro, T., Política económica, economía regional y servicios. Homenaje a Juan Ramón Cuadrado Roura, Aranzadi, Pamplona, 205-224.

ARRIBAS REYES, E. (2016): "Pactos de Integridad: tres décadas de experiencias en Europa como ejemplo para su implementación en España", Revista Internacional de Transparencia e Integridad, 1. En: http://revistainternacionaltransparencia.org/wp-content/uploads/2016/09/ESTEBANARRIBAS.pdf; extraído el 20/6/2017.

ARROYO MARTíNEZ, L. (1997): "Fábulas y fabuladores. El escándalo político como fenómeno de los medios de comunicación". En: Laporta \& Álvarez, 335-358.

ARTERO MUÑOZ, J.P. (2016): "Medios de comunicación, derecho a la información y corrupción". En: Villoría, Gimeno \& Tejedor, 109-124.

ARTÉS CASELLES, J. \& JIMÉNEZ GONZÁLEZ, J.L. (2017): "Efectos políticos y económicos de los escándalos de corrupción y de su difusión pública". En: Rodríguez García, N. \& Rodríguez López, F. (Coord.), Corrupción y desarrollo, Tirant lo Blanch, Valencia, 45-69. 
AUGER, C. (1997): "La justicia ante el fenómeno de la corrupción". En: Laporta \& Álvarez, 235-250.

BACIGALUPO, S. (2016): "Prevención de la corrupción en los negocios y en el sector público: buen gobierno y transparencia". En: Villoría, Gimeno \& Tejedor, 435-450.

BANFIELD, E.C. (1975): "Corruption as a Feature of Governmental Organization", The Journal of Law and Economics, 18: 587-605.

BARDHAN, P. (1997): "Corruption and Development: A Review of Issues", Journal of Economic Literature, 35(3): 1320-1346.

BAUMAN, Z. (2002): Modernidad líquida, Fondo de Cultura Económica España, Madrid.

BAUMAN, Z. (2017): Retropía. Espasa Libros, Barcelona.

BECCARIA, C. \& VOLTAIRE (2014): De los delitos y de las penas (1764); Comentarios al libro «De los delitos y de las penas" por un abogado de provincias (1766), Alianza Editorial, Madrid.

BECKER, G.S. (1968): "Crime and Punishment: An Economic Approach", The Journal of Political Economy, 76(2): 169-217.

BENTHAM, J. (1836): Deontología o Ciencia de la Moral (Tomo Primero), Librería de Mallen y Sobrinos, Valencia.

BENTHAM, J. (1965): Escritos económicos, Fondo de Cultura Económica, México.

BETANCOR, A. (2016): "Puertas giratorias: regulación y control", En: Villoría, Gimeno \& Tejedor, 157183.

BOE (2010): "Instrumento de Ratificación del Convenio penal sobre la corrupción (Convenio n 173 del Consejo de Europa) hecho en Estrasburgo el 27 de enero de 1999", Boletín Oficial del Estado, $n^{\circ} 182$, Miércoles 28 de julio.

BOE (2015): Ley Orgánica 1/2015, de 30 de marzo, por la que se modifica la Ley Orgánica 10/1995, de 23 de noviembre, del Código Penal.

BOE (2016): Ley Orgánica 10/1995, de 23 de noviembre, del Código Penal (última modificación: 28 de abril de 2015).

BOEHM, F. (2005): "Corrupción y captura en la regulación de los servicios públicos", Revista de Economía Institucional, 7(13): 245-263.

BOEHM, F. \& LAMBSDORFF, J.G. (2009): "Corrupción y anticorrupción: una perspectiva neo-institucional", Revista de Economía Institucional, 11(21): 45-72.

BOERNER, K. \& HAINZ, C. (2009): "The political economy of corruption and the role of economic opportunities", Economics of Transition, 17(2): 213-240.

BRANDT, U.S. \& SVENDSEN, G.T. (2016): The Politics of Persuasion. Should Lobbying be Regulated in the EU?, Edward Elgar Publishing, Northampton, MA. 
BUSSELL, J. (2015): “Typologies of corruption: a pragmatic approach”. En: Rose-Ackerman \& Lagunes (2015): 21-45.

CARTIER-BRESSON, J. (1997): "Corruption Networks, Transaction Security and Illegal Social Exchange", Political Studies, 45: 463-476.

CARTOLANO, M.J. (2012): "Los delitos de ejercicio y tráfico de influencias: estudio de las circunstancias que motivaron su criminalización y análisis dogmático". En: Zúñiga, L., Gorjón, M.C., Fernández, J. \& Díaz, L.M., Poder y delito: Escándalos financieros y políticos, Ratio Legis Librería Jurídica, Salamanca, 145-178.

CASTELLS OLIVÁN, M. (2015): Redes de indignación y esperanza. Los movimientos sociales en la era de Internet, Alianza Editorial, Madrid.

CASTILLO PRATS, S. (2013): Tierra de saqueo. La trama valenciana de Gürtel, 9 Grup Editorial, Barcelona.

CASTILLO PRATS, S. (2016): Yonquis del dinero. Las diez grandes historias de la corrupción valenciana, 9 Grup Editorial, Barcelona.

CE (Comisión Europea) (2014): Informe de lucha contra la corrupción de la UE (Anexo 9, España), COM(2014) 38 final, Bruselas.

COHEN, L.E. \& FELSON, M. (1979): "Social Change and Crime Rate Trends. A Routine Activity Approach", American Sociological Review, 44 (August): 588-608.

COLLIER, M.W. (2002): "Explaining corruption: An institutional choice approach", Crime, Law and Social Change, 38: 1-32.

CORNISH, D.B. \& CLARKE, R.V. (2003): "Opportunities, Precipitators and Criminal Decisions: A Reply To Wortley's Critique of Situational Crime Prevention", Crime Prevention Studies, 16: 41-96.

CORRECHER MIRA, J. (2015): "Análisis jurisprudencial de los delitos contra la Administración pública en el territorio valenciano". En: Jareño Leal, Á. (Dir.), Corrupción pública. Cuestiones de Política Criminal (II): la Comunitat Valenciana, lustel, Madrid, 21-79.

EKAIZER, E. (2015): Queríamos tanto a Luís, Planeta, Barcelona.

EUROPA PRESS (2012): "El fraude en investigaciones científicas se ha multiplicado por diez desde 1975", El Mundo, 4 de octubre de 2012. (http://www.elmundo.es/elmundo/2012/10/03/ciencia/1349254110.html, extraído el 14/6/2017).

FOX, J. (2007): "The uncertain relationship between transparency and accountability", Development in Practice, 17(4-5): 663-671. DOI: 10.1080/09614520701469955.

FOX, J. (2008): "Transparencia y rendición de cuentas". En: Ackerman, J.M. (Coord.), Más allá del acceso a la información: Transparencia, rendición de cuentas y Estado de derecho, Siglo XXI, México, 174-198. 
GALLERO, M. (2015): Bárcenas. La caja fuerte. Los papeles secretos del tesorero del PP, La Esfera de los Libros, Madrid.

GARZÓN, B. (2015): El fango. Cuarenta años de corrupción en España, Penguin Random House Grupo Editorial, Barcelona.

GARZÓN, B. (2016): En el punto de mira, Editorial Planeta, Barcelona.

GIMENO FELIU, J.M. (2016): "El necesario big-bang contra la corrupción en materia de contratación pública y su modelo de control", Revista Internacional de Transparencia e Integridad, 2, En: http://revistainternacionaltransparencia.org/wp-content/uploads/2016/12/Jose-María-Gimeno-1 ${ }^{\text {a }}$ artículo.pdf, extraído el 20/6/2017.

GOMA, R. \& SUBIRATS, J. (Coords.) (1998): Políticas públicas en España. Contenidos, redes de actores y niveles de gobierno, Ariel, Barcelona.

GONZÁLEZ DE ASÍS, M. (2001): "Construcción de coaliciones para luchar contra la corrupción", Gestión y Política Pública, 10(2): 309-320.

GORE, M.L., RATSIMBAZAFY, J. \& LUTE, M.L. (2013): "Rethinking Corruption in Conservation Crime: Insights from Madagascar", Conservation Letters, 6(6): 430-438. DOI: 10.1111/conl.12032.

GRAMSCI, A. (2011): Odio a los indiferentes, Editorial Ariel, Barcelona.

GRAU, M., Í̃IIGUEZ-RUEDA, L. \& SUBIRATS, J. (2010): "La perspectiva sociotécnica en el análisis de políticas públicas", Psicología Política, 41: 61-80.

GRAY, C.W. \& KAUFMANN, D. (1998): "Corrupción y desarrollo", Finanzas y Desarrollo, Marzo de 1998: 7-10.

GRECO (Group of States against Corruption) (2016): Fourth Evaluation Round. Corruption prevention in respect of members of parliament, judges and prosecutors. Compliance Report Spain, GRECO Secretariat, Council of Europe, Strasbourg.

GUICHOT, E. (2016): "Transparencia y acceso a la información pública en el marco de la lucha contra la corrupción". En: Villoría, Gimeno \& Tejedor, 141-156.

HIRSCHMAN, A.O. (1977): Salida, voz y lealtad. Fondo de Cultura Económica, México.

HIRSCHMAN, A.O. (1981): La estrategia del desarrollo económico, Fondo de Cultura Económica, México.

HOLMES, L. (Ed.) (2007): Terrorism, Organised Crime and Corruption. Networks and Linkages, Edward Elgar Publishing Limited, Massachusetts.

HUALING, F. (2015): "Wielding the sword: President Xi's new anti-corruption campaign". En: RoseAckerman \& Lagunes, 134-157. 
IGLESIAS, F. (Dir.) (2007): Urbanismo y democracia. Alternativas para evitar la corrupción (Vol. I). Fundación Alternativas, Madrid, http://www.fundacionalternativas.org/las-publicaciones/informes/informe-urbanismo-y-democracia-alternativas-para-evitar-la-corrupcion-vol-i; extraído el $14 / 6 / 2017$.

JAIN, A.K. (Ed.) (1998): Economics of Corruption, Kluwer Academic Publishers, Norwell.

JEAMBAR, D. \& ROUCAUTE, Y. (1999): Elogio de la traición. Sobre el arte de gobernar por medio de la negación, Gedisa, Barcelona.

JIMÉNEZ DE PARGA, M. (1997): “La corrupción en la democracia”. En: Laporta \& Álvarez, 135-155.

JIMÉNEZ SÁNCHEZ, F. (1997): "Posibilidades y límites del escándalo político como una forma de control social". En: Laporta \& Álvarez, 293-334.

JIMÉNEZ SÁNCHEZ, F. (2008): "Boom urbanístico y corrupción política en España". En: Pérez-Díaz, V. (coord.), Modernidad, crisis y globalización: problemas de política y cultura; Mediterráneo Económico, 14: 263-285.

JOHNSTON, M. (2013): "How do I vote the scoundrels out? Why voters might not punish corrupt politicians at the polls", Crime, Law and Social Change, 60:503-514. DOI:10.1007/s10611-013-9477-3.

KAUFMANN, D. (1997): "Corruption: The facts", Foreign Policy, 107: 114-131.

KLITGAARD, R. (1998): "International Cooperation Against Corruption", Finance and Development, 35(1): 3-6.

LAGUNES, P. \& HUANG, R. (2015): "Saving Gotham: fighting corruption in New York City's property tax system". En: Rose-Ackerman \& Lagunes, 180-205.

LAMBSDORFF, J.G. (2007): The Institutional Economics of Corruption and Reform. Theory, Evidence, and Policy, Cambridge University Press, Cambridge.

LAPALOMBARA, J. (1994): "Structural and Institutional Aspects of Corruption", Social Research, 61(2): 325-350.

LAPORTA, F.J. \& ÁLVAREZ, S. (Eds.) (1997): La corrupción política, Alianza Editorial, Madrid.

LAPUENTE, V. (Coord.) (2016): La corrupción en España. Un paseo por el lado oscuro de la democracia y el gobierno, Alianza Editorial, Madrid.

LEDERMAN, D., LOAYZA, N. \& REIS SOARES, R. (2001): "Accountability and Corruption: Political Institutions Matter", Policy Research Working Paper, 2708, November, The World Bank, Washington DC.

LÓPEZ ÁLVAREZ, A. (2016): "Los partidos políticos en España: constitucionalización, régimen legal, democracia interna y corrupción". En: López Álvarez, A. \& García Navarro, J.J. (Coord.) (2016): La corrupción política en España: una visión ética y jurídica, Thomson Reuters-Aranzadi, Pamplona, 35-49. 
MARCH POQUET, J.M. (2015): "Crisis, ajuste y políticas económicas alternativas: la lucha contra la corrupción". En: Bono Martínez, E., Sánchez Andrés, A. \& Tomás Carpi, J.A. (2015): Renovación de la Política Económica y cambios sociales. Ensayos en honor de Josep María Jordán, Tirant Io Blanch, Valencia, 93-101.

MARCH POQUET, J.M. (2017): "Política económica y delito político". En: Bono Martínez, E. \& Sánchez Andrés, A. (Coord.), Política Económica frente al neoliberalismo. Ensayos en homenaje a Juan Antonio Tomás Carpi, Tirant lo Blanch, Valencia, 177-188.

MATUS, C. (1980): Planificación de situaciones, Fondo de Cultura Económica, México.

McGEE, R. \& GAVENTA, J. (2011): "Shifting Power? Assessing the Impact of Transparency and Accountability Initiatives", IDS Working Paper, $n^{\circ} 383$, Institute of Development Studies.

MEDELLÍN TORRES, P. (2004): La política de las políticas públicas: propuesta teórica y metodológica para el estudio de las políticas públicas en países de frágil institucionalidad, Naciones Unidas, Santiago de Chile.

MENA ÁLVAREZ, J.M. (2010): De oficio fiscal, Ariel, Barcelona.

MÉNDEZ RODRÍGUEZ, C. (2014): "Los delitos de pertenencia a organización criminal y a grupo criminal y el delito de tráfico de drogas cometido por persona que pertenece a una organización delictiva. Crónica de un conflicto normativo anunciado y análisis jurisprudencial", Estudios Penales y Criminológicos, 34: 511-560.

MIR, S. \& CRUZ, G. (2012): La casta autonómica. La delirante España de los chiringuitos locales, La Esfera de los libros, Madrid.

MOENE, K. \& SØREIDE, T. (2015): "Good governance facades". En: Rose-Ackerman \& Lagunes, 4670.

OCDE-UNODC-BANCO MUNDIAL (2013): Ética anticorrupción y elementos de cumplimiento. Manual para empresas, https://www.unodc.org/documents/corruption/Publications/2014/EticaAnticorrupcion-Elementos-Cumplimiento.pdf, extraído el 16/6/2017.

OLIVER, D. (1997): "Regulating the Conduct of MPs. The British Experience of Combating Corruption", Political Studies, 45: 539-558.

PERIS, V. (Dir.) (2017): "La estrategia del silencio". Documental producido por Barret Films y Mediapro, emitido el 28/5/2017 en Salvados, La Sexta, Madrid. Disponible en http://www.lasexta.com/programas/la-estrategia-del-silencio. Acceso: 30/5/2017.

PONCE SOLÉ, J. (2016): "Las agencias anticorrupción. Una propuesta de lista de comprobación de la calidad de su diseño normativo", Revista Internacional de Transparencia e Integridad, 3. En: http://revistainternacionaltransparencia.org/wp-content/uploads/2017/04/Julio-Ponce.pdf; extraído el 20/6/2017. 
PRADERA, J. (1997): "La maquinaria de la democracia. Los partidos en el sistema político español". En: Laporta y Álvarez, 157-185.

PRADERA, J. (2014): Corrupción y política. Los costes de la democracia, Galaxia Gutenberg, Barcelona.

QUERALT, J.J. (2016): "Public Compliance y corrupción: análisis conceptual y propuestas", Revista Internacional de Transparencia e Integridad, 2, En: http://revistainternacionaltransparencia.org/wpcontent/uploads/2016/12/Joan-Queralt.pdf; extraído el 20/6/2017.

RASILLO LÓPEZ, P. (2016): "Los delitos de corrupción tras la reforma del Código Penal por LO 1/2015", Revista de Jurisprudencia, 2 (15 de octubre), http://revistas.elderecho.com/revistas/revistadejurisprudencia/numero_2-_octubre_2016/delitoscorrupcion-reforma-Codigo-Penal_11_1016680004.html; extraído el 6/10/2017.

RIDAO MARTÍN, J. (2015): "Razones para una crisis de la democracia representativa en España: Entre la partitocracia y la corrupción", Pensamiento Americano, 8(14): 109-122.

RODRÍGUEZ GARCÍA, N. (2016): "En la búsqueda de un sistema penal más eficaz en el combate a la corrupción: expectativas depositadas en el decomiso", Revista Internacional de Transparencia e Integridad, 1, http://revistainternacionaltransparencia.org/wp-content/uploads/2016/09/NicolásRodríguez-García.pdf, extraído el 15/6/2017.

ROSE-ACKERMAN, S. \& LAGUNES, P. (Eds.) (2015): Greed, Corruption, and the Modern State. Essays in Political Economy, Edward Elgar Publishing, Massachusetts.

ROSE-ACKERMAN, S. \& TRUEX, R. (2012): "Corruption and Policy Reform”, Working Paper Prepared for the Copenhagen Consensus Project, February 17, http://ssrn.com/abstract=2007152; extraído el 14/04/2017.

RUIZ-FUNES, M. (2013): Evolución del delito político, Fondo de Cultura Económica de España Cátedra del Exilio, Madrid.

SALVADOS (2013): "Los olvidados". Documental emitido el 28/4/2013 en Salvados, La Sexta, Madrid. Disponible en: http://www.atresplayer.com/television/programas/salvados/temporada-6/capitulo27-los-olvidados_2013091900416.html, Acceso: 8/6/2017.

SAMPEDRO, J.L. et al. (2011): Reacciona. 10 razones por las que debes actuar frente a la crisis económica, política y social, Altea Taurus Alfaguara, Madrid.

SEN, A. (2000): Desarrollo y libertad, Planeta, Barcelona.

SERNA, J. (2013): La farsa valenciana. Los personajes del drama, Ediciones Akal, Madrid.

SHAH, A. (Ed.) (2007): Participatory Budgeting, The International Bank for Reconstruction and Development / The World Bank, Washington DC.

SHLEIFER, A. \& VISHNY, R.W. (1993): "Corruption", The Quarterly Journal of Economics, 108(3): 599-617. 
SORIANO, R. (2011): "La corrupción política: tipos, causas y remedios", Anales de la Cátedra Francisco Suárez, 45: 382-402.

SUBIRATS, J., KNOEPFEL, P., LARRUE, C. \& VARONE, F. (2012): Análisis y gestión de políticas públicas, Ariel, Barcelona.

TAHIRI, J. (2017): "Montoro propone al Congreso prohibir por ley las amnistías fiscales en el futuro", $A B C, 21$ de junio.

TANZI, V. (1998): "Corruption Around the World. Causes, Consequences, Scope, and Cures", International Monetary Fund, IMF Staff Papers, 45(4): 559-594.

TI (Transparency International) (2013): Global Corruption Report: Education, Routledge, New York.

TIE (Transparencia Internacional España): (2011): El Marco de Integridad Institucional en España: Situación Actual y Recomendaciones. Resumen Ejecutivo, Transparencia Internacional España. (https://www.transparency.org/whatwedo/publication/marco_de_integridad_institucional_en_espana; extraído el 16/6/2017).

TIE (2012): El Marco Institucional de Integridad en España: Situación Actual y Recomendaciones, Tirant lo Blanch, Valencia.

TIE (2017): Novedad Sector Privado: Publicada la norma UNE 19601, http://transparencia.org.es/wpcontent/uploads/2017/05/novedad_sector_privado_norma_une-19601.pdf; extraído el 1/6/2017.

URIARTE BENGOCHEA, E. (2002): Introducción a la Ciencia Política: la política en las sociedades democráticas, Tecnos, Madrid.

VILLORIA MENDIETA, M. (2006): La corrupción política, Editorial Síntesis, Madrid.

VILLORIA MENDIETA, M., GIMENO FELIU, J.M. \& TEJEDOR BIELSA, J. (Dir.) (2016): La corrupción en España. Ámbitos, causas y remedios jurídicos, Atelier, Barcelona.

VON HAYEK, F.A. (1956): "Friedrich von Wieser", Revista de Economía Política, 7(2-3): 524-539.

VON MISES, L. (2005): Burocracia: gestión empresarial frente a gestión burocrática, Unión Editorial, Madrid.

WALSH, A. \& HEMMENS, C. (2011): Introduction to Criminology, SAGE Publications, Thousand Oaks.

WILDEMEERSCH, J. (2016): "Bref propos conclusif sur les fonctions politiques des juges. Le juge et le citoyen: qui se trouve de l'autre côté du miroir?". En: Grandjean, G. \& Wildemeersch, J. (2016), Les juges: décideurs politiques? Essais sur le pouvoir politique des juges dans l'exercice de leur fonction, Éditions Bruylant, Bruselas, 347-358. 